\title{
Independent Technical Review of the X-740 Groundwater Remedy, Portsmouth, Ohio: Technical Evaluation and Recommendations
}

March 2010

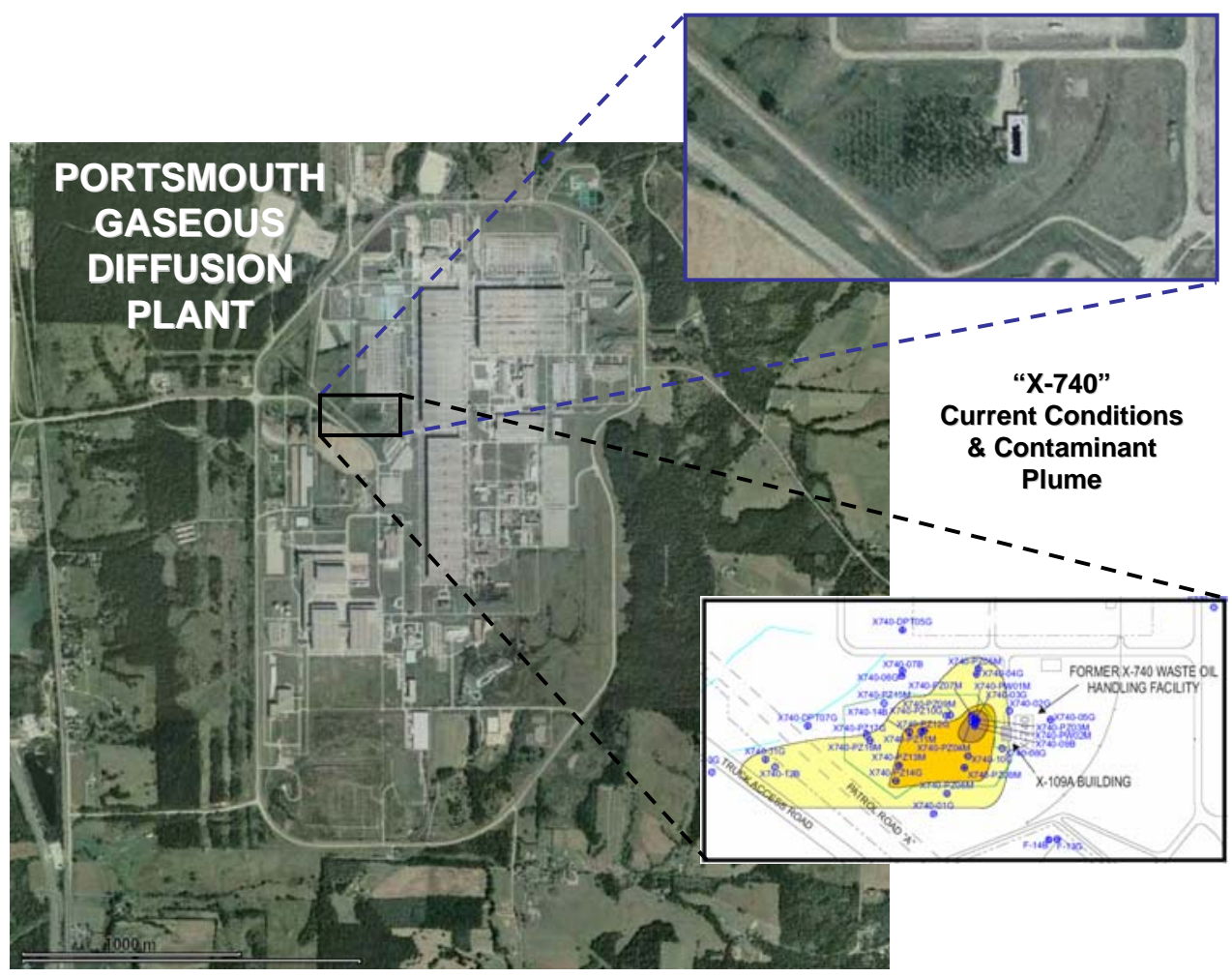

Prepared for: The U.S. Department of Energy Office of Environmental Management Groundwater and Soil Remediation Technology (EM32), Washington, DC

Prepared by: The DOE EM Center for Sustainable Groundwater and Soil Solutions, Savannah River National Laboratory, Aiken SC

Technical content and coordination for this effort was provided by the Savannah River National Laboratory in conjunction with Contract No. DE-AC09-08SR22470 with the U.S. Department of Energy. 

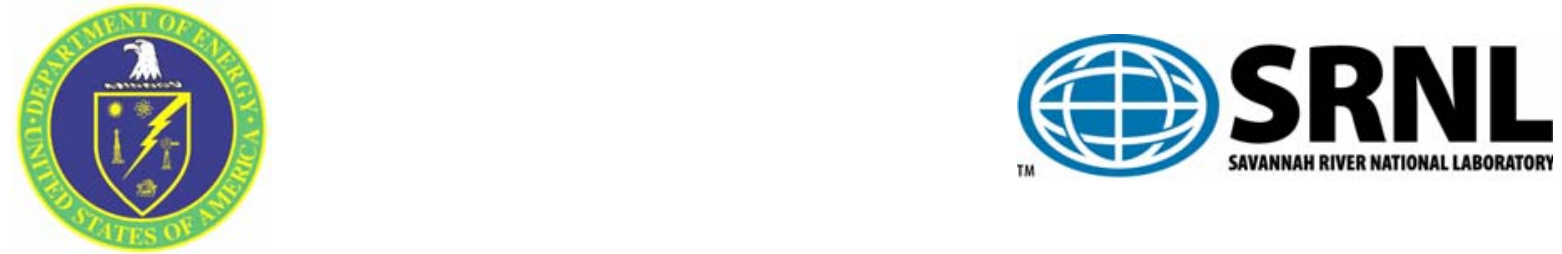

\section{Cover:}

Aerial photograph of the Portsmouth Gaseous Diffusion Plant showing the approximate location of the groundwater plume near the former X-740 waste oil handling facility. Insets provide a magnified aerial view of the plume area, as well as a groundwater plume map.

\section{DISCLAIMER}

This work was prepared under an agreement with and funded by the U.S. Government. While the authors have taken care in the preparation of this report, neither the U. S. Government or its employees, nor any of its contractors, subcontractors or their employees, makes any express or implied: 1. warranty or assumes any legal liability for the accuracy, completeness, or for the use or results of such use of any information, product, or process disclosed; or 2. representation that such use or results of such use would not infringe privately owned rights; or 3. endorsement or recommendation of any specifically identified commercial product, process, or service. Any views and opinions of authors expressed in this work do not necessarily state or reflect those of the United States Government, or its contractors, or subcontractors.

Printed in the United States of America

Prepared For

U.S. Department of Energy

Office of Engineering and Technology 


\title{
Independent Technical Review of the X-740 Groundwater Remedy, Portsmouth, Ohio: Technical Evaluation and Recommendations
}

\author{
Authors: \\ Brian B Looney (Technical Lead) ${ }^{1}$ \\ Dennis G. Jackson ${ }^{1}$ \\ Brian D. Riha ${ }^{1}$ \\ Rosa Ramirez ${ }^{2}$ \\ Latrincy Whitehurst $^{2}$ \\ Carol A. Eddy-Dilek ${ }^{1}$
Prepared for
Claude Magnuson
Department of Energy (DOE) Office of Groundwater and
Soil Remediation
Washington, D.C. \\ March 2010

\footnotetext{
${ }^{1}$ Savannah River National Laboratory, Aiken SC

${ }^{2}$ US DOE EM, Washington DC
} 
\{blank page 


\section{Table of Contents}

Executive Summary

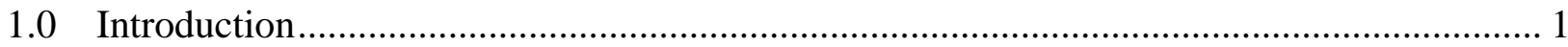

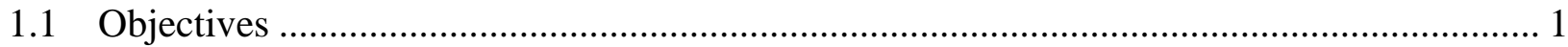

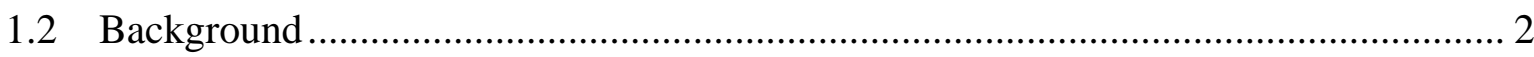

General Site History and Facility Regulatory Issues

Geology

Linkage of Contaminant Releases to Subsurface Contamination

2.0 Review Team Conceptual Model(s) ......................................................................... 5

2.1 Conceptual Model Development Process .............................................................. 5

2.2 Contaminant Hydrology $\quad$............................................... 6

2.3 Impact of Conceptual Models on Remedial Strategy .......................................... 10

2.4 Recent Technology Selection Efforts .......................................................... 11

Preliminary screening

Alternative Screening

Detailed Analysis of Alternatives

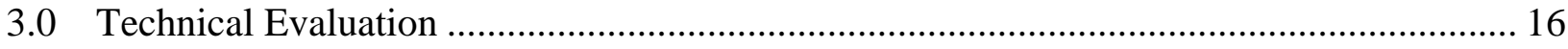

3.1 Review Team Statement on Technical Impracticability ..................................... 16

3.2 Review Team Technical Evaluation Process ......................................................... 17

Key points that guided the review team evaluation

3.3 Review Team Technical Evaluation Results ...................................................... 18

Containment

In Situ Chemical Treatment

In Situ Thermal Treatment

Bioremediation

Permeable Reactive Barrier

Access and Delivery

4.0 Consolidated Recommendations and Example Combined Remedy................................ 30

4.1 Summary of Review Team Findings and Recommendations................................ 30

4.2 Combined Remedy Example for the X-740 Plume …............................................ 33 


\section{List of Figures}

Figure 1. Location and current conditions in the vicinity of the former X-740 facility............ 3

Figure 2. Generalized Stratigraphic Section for X-740 ............................................... 4

Figure 3. Summary conceptual model for TCE in the soil and groundwater........................... 7

Figure 4. Overlay of storm drain system, local streams, and August 2006 potentiometric

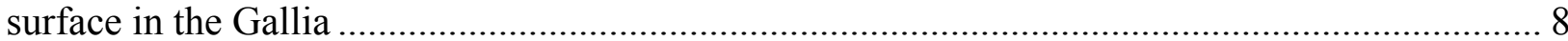

Figure 5. Gallia and Berea hydrographs and Berea concentration response to seasonal water level fluctuations for wells in the X-740 source area............................................... 9

Figure 6. Plan view map depicting source and down gradient treatment targets.................... 12

Figure 7. Image showing the lifecycle of a contaminant plume and a continuum of possible technologies matched to different target zone. ................................................... 13

Figure 8. Piezometric surfaces in the Gallia Formation near X-740................................. 21

Figure 9. Relative mobility and longevity of various electron donor substrates.................... 26

Figure 10. Schematic of TCE concentration reduction processes using structured

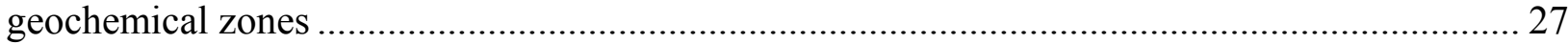

Figure 11. Simplified schematic of anaerobic bioremediation targeting the Gallia in the

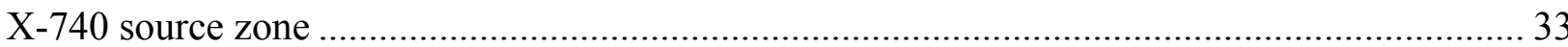

Figure 12. Detailed diagram of hypothetical X-740 source zone anaerobic bioremediation....... 35

Figure 13. Field operations schedule for hypothetical deployment ..................................... 37 


\section{List of Tables}

Table 1. Geochemical Parameters for Reductive Dechlorination...................................... 27

Table 2. Consolidated results of the EM-32 X-740 Technical Review.............................. 31

Table 3. Parameters supporting hypothetical design ...................................................... 36 


\section{Acronyms and Abbreviations}

AFCEE

$\mathrm{COC}$

$\mathrm{C}_{\mathrm{s}}$

$\mathrm{cu}$

$\mathrm{cVOC}$

$\mathrm{C}_{\mathrm{w}}$

DNAPL

DOE

EM-30

EPA

FY

Gal

$\mathrm{Gpm}$

$\mathrm{H}_{2} \mathrm{O}_{2}$

ITRC

$\mathrm{K}_{\mathrm{d}}$

$\mathrm{kg}$

$\mathrm{KMnO}_{4}$

LIF

MIP

$\mathrm{MnO}_{2}$

Msl

$\mathrm{NaMnO}_{4}$

NAPL

OEPA

PGDP

PITT

PPPO

PRB

PRG

RCRA

RTDF

TCE

TOD

VOC

$\mathrm{wt} \%$

Yds

$\mu \mathrm{g} / \mathrm{kg}$

$\mu \mathrm{g} / \mathrm{L}$
Air Force Center for Environmental Excellence

Contaminant of concern

Contaminant concentration in soil

Cubic

Chlorinated volatile organic compound

Contaminant concentration in groundwater

Dense nonaqueous phase liquid

U.S. Department of Energy

DOE Office of Groundwater and Soil Remediation

Environmental Protection Agency

Fiscal year

Gallon

Gallons per minute

Hydrogen peroxide

Interstate Technology and Regulatory Council

Partition coefficient of a contaminant between soil and groundwater

Kilogram

Potassium permanganate

Laser induced fluorescence

Membrane interface probe

Manganese dioxide

Mean sea level

Sodium permanganate

Nonaqueous phase liquid

Ohio Environmental Protection Agency

Portsmouth Gaseous Diffusion Plant

Partitioning interwell tracer test

Portsmouth Paducah Project Office

Permeable reactive barrier

Preliminary remediation goal

Resource Conservation and Recovery Act

Remediation Technologies Development Forum

Trichloroethene

Total oxidant demand

Volatile organic contaminant

Percent by weight

Yards

Micrograms per kilogram

Micrograms per liter 


\section{Executive Summary}

Two major remedial campaigns have been applied to a plume of trichloroethene (TCE) contaminated groundwater near the former X-740 facility at the Portsmouth Gaseous Diffusion Plant in Piketon Ohio. The two selected technologies, phytoremediation using a stand of hybrid poplar trees from 1999-2007 and in situ chemical oxidation using modified Fenton's Reagent from 2008-2009, have proven ineffective in achieving remedial action objectives (RAOs). The "poor" performance of these technologies is a direct result of site specific conditions and the local contaminant hydrogeology. Key among these challenges is the highly heterogeneous subsurface geology with a thin contaminated aquifer zone (the Gallia) - the behavior of the contamination in the Gallia is currently dominated by slow release of TCE from the clay of the overlying Minford formation, from the sandstone of the underlying Berea formation, and from clayey layers within the Gallia itself.

In response to the remediation challenges for the X-740 plume, the Portsmouth team (including the US Department of Energy (DOE), the site contractor (CDM), and the Ohio Environmental Protection Agency (OEPA)) is evaluating the feasibility of remediation at this site and identifying specific alternatives that are well matched to site conditions and that would maximize the potential for achieving RAOs. To support this evaluation, the DOE Office of Groundwater and Soil Remediation (EM-32) assembled a team of experts to serve as a resource and provide input and recommendations to Portsmouth. Despite the challenging site conditions and the failure of the previous two remediation campaigns to adequately move the site toward RAOs, the review team was unanimous in the conclusion that an effective combination of cost effective technologies can be identified. Further, the team expressed optimism that RAOs can be achieved if realistic timeframes are accepted by all parties.

The initial efforts of the review team focused on reviewing the site history and data and organizing the information into a conceptual model and findings to assist in evaluating the potential of alternative remediation technologies. Examples of the key conceptual findings of the EM-32 review team were:

o The Gallia represents the most practical target for deployment of in situ remediation treatment reagents -injection/extraction focused in this zone would provide maximum lateral impacts with minimal potential risk of failure or adverse collateral impacts.

o The slow release of TCE from clay and sandstone into the Gallia represent a long term source of TCE that can re-contaminate the Gallia in the future - technologies that effectively treat the permeable portions of the Gallia, but do not leave residual treatment capacity in the system are unlikely to achieve long term remedial action objectives.

$\mathrm{CDM}$, the site contractor, provided important and useful information documenting the status and preliminary results of the on-site technology alternative evaluation. In the CDM evaluation, potential technologies were either retained (or screened out) in two preliminary evaluation phases and a detailed evaluation was performed on the five 
alternatives that were retained into the final "detailed analysis" phase. The five alternatives that were included in the detailed analysis were: 1) hydraulic fracturing with EHC (a solid bioremediation amendment), 2) enhanced anaerobic bioremediation, 3) in situ chemical oxidation, 4) electrical resistance heating, and 5) reactive barriers. In several cases, two or three variants were separately evaluated. The review team found the CDM effort to be generally credible and reasonable. Thus, the review team focused on providing additional considerations and inputs to Portsmouth and on amending and refining the alternatives in ways that might improve performance and/or reduce costs.

Three technologies were classified by the DOE EM-32 review team as "potentially viable and conditionally recommended." These were:

o Enhanced Anaerobic Bioremediation -- In situ bioremediation using long lived electron donor and low pressure liquid deployment

o Permeable Reactive Barriers -- Treatment zone installed downgradient designed to reduce/destroy contaminants flowing through the zone.

o Passive Upgradient Drains - Collection system designed to divert water around the contaminant source zone and plume

The remaining technologies that were determined to be potentially viable by either the CDM analysis or the EM-32 review team analysis were all classified as "potentially viable but not recommended." These not recommended technologies included all forms of oxidant, heating, bioremediation with short lived substrates, and technologies requiring fracturing. The review team encouraged consideration of a combined remedy and provided an illustrative example that includes enhanced anaerobic bioremediation in the source zone, enhanced attenuation in the downgradient plume and possible use of a passive upgradient drain. A properly configured combined remedy maximizes the potential to efficiently move toward RAOs. Importantly, the DOE EM-32 review team encourages consideration of our findings and recommendations, but does not view them as prescriptive. Instead, we hope that the effort can serve as a catalyst to encourage the Portsmouth team -- DOE, contractor and regulators -- to work together to develop a creative and effective solution that is custom fit to address the challenges of remediation of the X-740 source and plume.

The key to implementing a creative, effective and robust solution will be explicit and careful matching of technologies to the unique characteristics of the X-740 source area and plume. The performance of previous remediation technologies at X-740 and the eventual determination by OEPA and DOE that these technologies were ineffective is both cautionary and instructive. Because of the issues described above, the poor performances to date are not necessary and sufficient documentation to justify technical impracticability. Instead, the site is at a critical juncture in which DOE, the contractor and OEPA have an opportunity to put the lessons to use to develop a strategy that has a significant potential for success. 


\section{$1.0 \quad$ Introduction}

\section{$1.1 \quad$ Objectives}

The Department of Energy Portsmouth Paducah Project Office requested assistance from Department of Energy Office of Environmental Management (EM-32) to provide an independent technical panel to review previous and ongoing remedial activities designed to address TCE contamination in groundwater at X-740. In 1999, a corrective action was implemented at X-740 to address contamination in the groundwater. The DOE planted poplar trees over 2.6 acres of the groundwater plume. After several years of groundwater monitoring, the results indicated that the benefits of phytoremediation were limited and insufficient to meet remedial objectives. In 2007, an alternative remedial strategy based on in situ oxidative treatment was negotiated with Ohio EPA. During FY2008, three treatment phases of chemical oxidation were completed. The general charter for the independent technical review team is to review the results of s previous and ongoing remedial actions to determine whether the current strategy will be effective in meeting the end points specified in the regulatory work plan.

The specific goals for review team are to:

- Review the X-740 Work Plan for the remedy with specific emphasis on the determination of the end point.

- Review the letter report from Ohio EPA following the third series of injection events.

- Review groundwater data from the baseline, Phase I, II, and III sampling events.

- Determine the feasibility of declaring "Technical Impracticability" and proceeding with RSI Independent Review Report.

- Provide a summary of other cost effective technologies that might be considered/implemented.

A selected group of technical experts attended a technical workshop at the Portsmouth Gaseous Diffusion Plant from December 8 through 10, 2009. During the first day of the workshop, both contractor and DOE site personnel briefed the workshop participants and took them on a tour of the X-740 site. The initial briefing was attended by representatives of Ohio EPA who participated in the discussions. On subsequent days, the team reviewed baseline data and reports, were provided additional technical information from site personnel, evaluated work plans, determined critical issues and uncertainties, and recommended alternatives. This report documents the findings and recommendations of the independent technical review team.

The review team acknowledges and appreciates the support of the Portsmouth team. We are grateful to both DOE (particularly, Amy Lawson and Melda Rafferty), to the project personnel from CDM (Steven Thompson and Del Baird), and to the Ohio EPA (Maria Galanti and Doug Snyder) for hosting the meeting and for their openness in providing access to the site data. This high level and high quality of support was key to the success of the technical review. 


\subsection{Background}

General Site History and Facility Regulatory Issues

The Portsmouth Gaseous Diffusion Plant (PGDP) has operated since January 1955 as a uranium enrichment facility. The X-740 operable unit is located on the western half of the DOE site (Figure 1) and includes both the former X-740 building and drum storage area. The X-740 Hazardous Waste Storage Tank was located in the northwest corner of the X-740 storage facility. The tank was used to collect residual water, oil, solvents, and PCB-contaminated waste oils from a drum crushing operation. Effluent from the drum crusher was discharged to a tank/sump located beneath the drum crusher pad.

The closure plan for the site included the $\mathrm{D} \& \mathrm{D}$ of the facility followed by removal of two feet of soil below the building excavation surface to confirm removal of all contaminants. Subsequent characterization identified contaminated soil at levels above the remedial limit specified in the closure plan. In order to comply with the Resource Conservation and Recovery Act (RCRA) health-based closure standards, a human health risk assessment was conducted in accordance with the Environmental Protection Agency (EPA) guidance. The risk assessment concluded that human health risks from residual contamination did not exceed EPA target values. A RCRA Closure Plan for X-740 was submitted by DOE in 1993 and approved by EPA in June 1994; however, further investigation was required to determine the nature and extent of soil and groundwater contamination found under and near the X740 facility.

Subsequent site characterization activities identified and delineated a TCE plume in the groundwater. Phytoremediation was selected as the preferred alternative and was implemented by planting a stand of hybrid polar trees. Periodic groundwater sampling after ten years of monitoring indicated that poplar trees were not significantly impacting the concentration of TCE in the groundwater. Consequently, the Ohio EPA required further action; including aquifer pump tests, improved groundwater modeling, and the implementation of additional treatment. Subsequently, in situ chemical oxidation (ISCO) using hydrogen peroxide was selected and implemented at the site, and resulted in a negligible reduction of the source mass at the X-740. The lack of efficacy of the treatment was interpreted to result from aquifer conditions that limit contact between the short-lived treatment reagent and the target TCE contaminant. As a result, the ISCO process was discontinued, and DOE and OEPA are currently exploring other alternatives. 


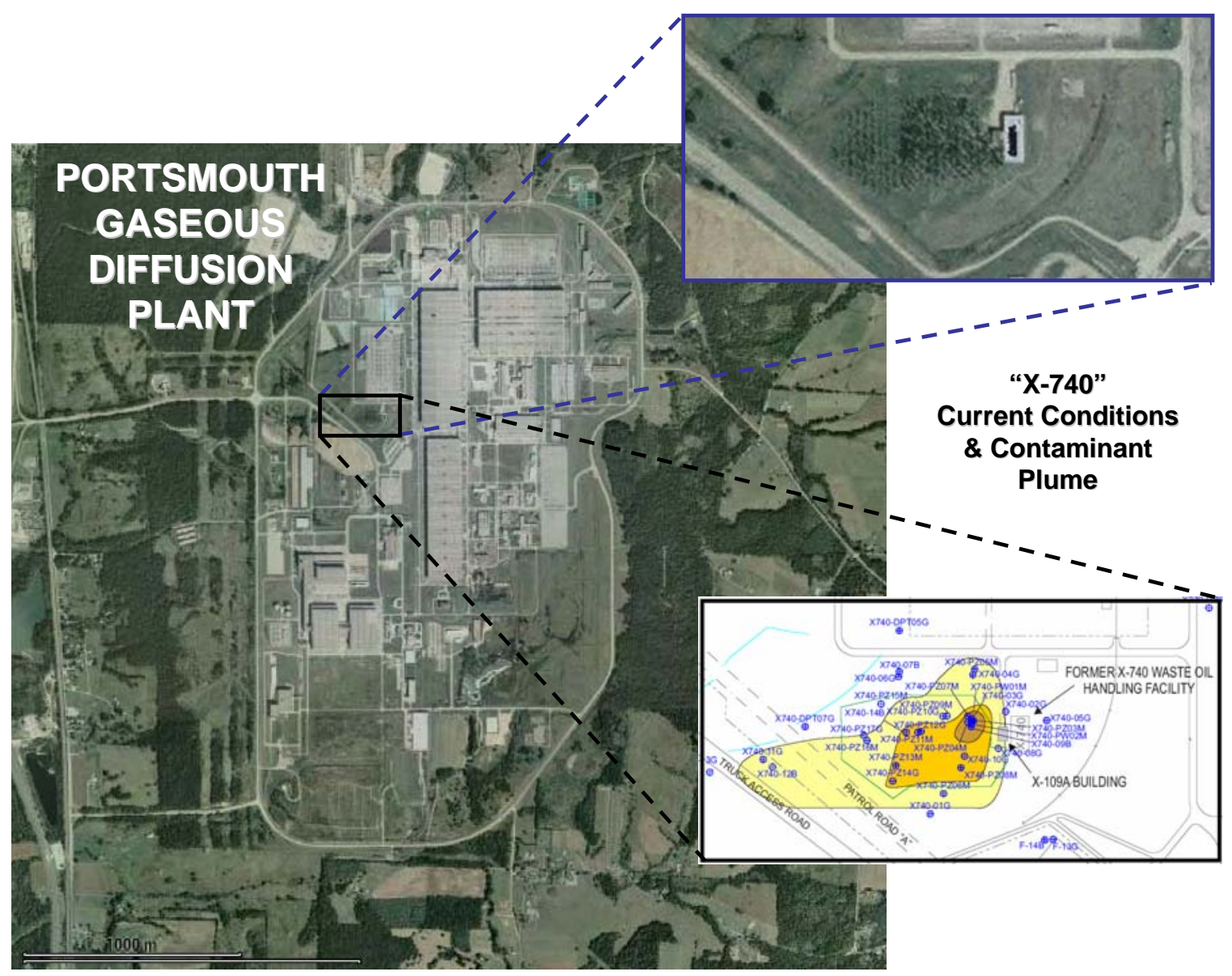

Figure 1. Location and current conditions in the vicinity of the former X-740 facility at the DOE PGDP

\section{Geology}

The geology at the X-740 site is composed of a section of unconsolidated sedimentary units that unconformably overlie consolidated bedrock units (Figure 2). The uppermost bedrock unit is the Berea Sandstone, a light grey, thickly bedded, fine-grained sandstone with thin shale laminations. The top ten to fifteen feet consists of a massive sandstone bed with few joints or shale laminae. The Berea Sandstone averages 35 feet in thickness.

The Gallia member of the Teays Formation overlies the Berea Sandstone and consists of fluvial silt, sand, and gravel that were deposited on the erosional surface of the underlying sandstone bedrock. The Gallia is composed of red-brown sand and clayey sand, poorly sorted gravel, and pebble size cobbles and fragments that ranges in thickness at X-740 from 0-5 feet. Due to nature of fluvial deposition systems where sediments laterally aggrade, the sediments in the Gallia are extremely heterogeneous laterally, ranging from clay to sand over very short distances. 
The Gallia member is overlain by the Minford member of the Teays Formation, consisting of unconsolidated lacustrine deposits of primarily silt and clay. The basal 10 to $15 \mathrm{ft}$ of the Minford member commonly consists of very fine sand and silt. The silt progressively becomes more clayey and grades upward into a series of laminated clay. The Minford is approximately 20 to 35 feet thick at the X-740 site. During initial site grading operations, the upper portion of the Minford was rework down to depths of 10-20 feet. In most cases, the reworked sediments are indistinguishable for the underlying Minford sediments.

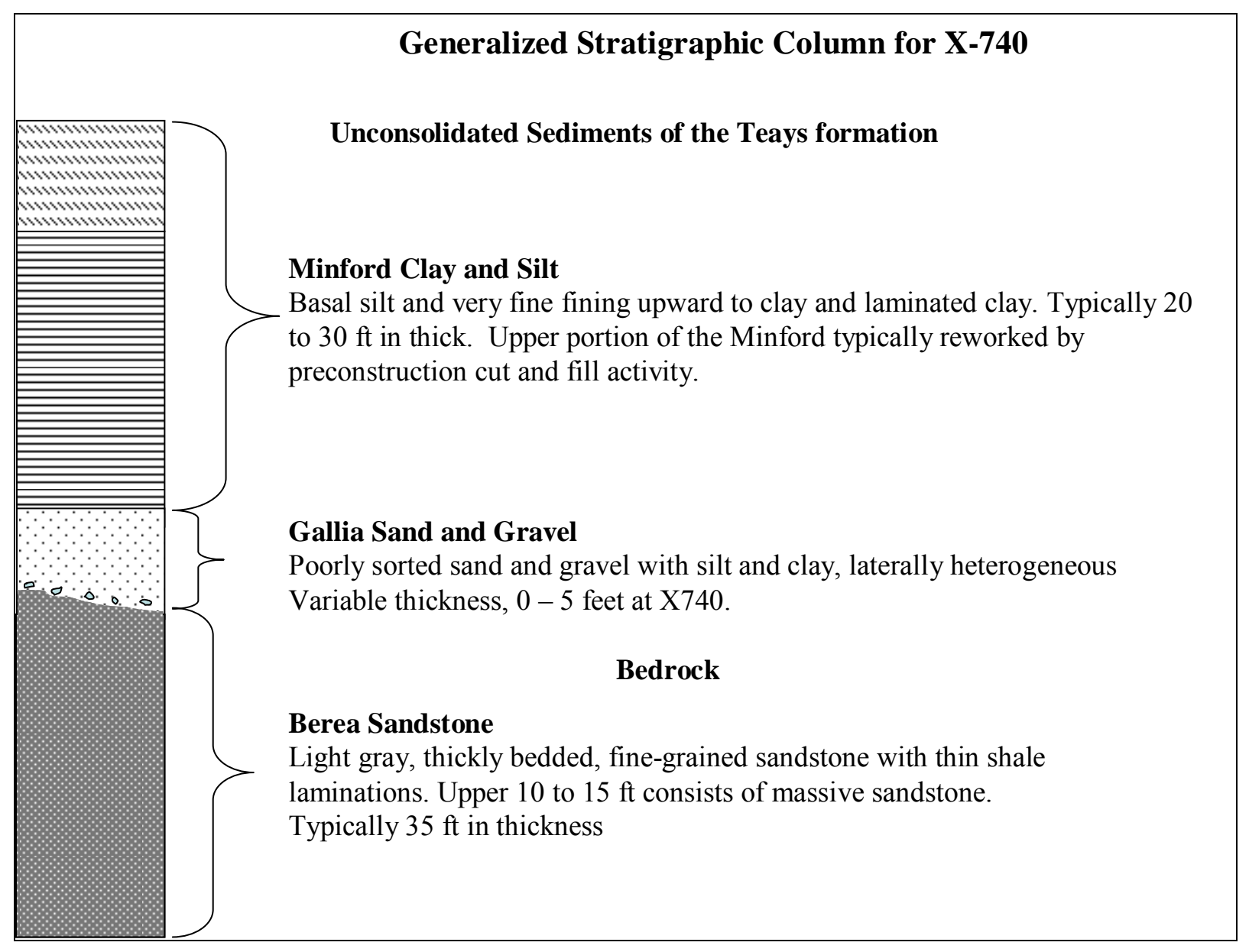

Figure 2. Generalized Stratigraphic Section for X-740. 


\section{Linkage of Contaminant Releases to Subsurface Contamination}

Contaminants released (via building footers and sumps) to the subsurface in the vicinity of X-740 passed through the heterogeneous clay- and silt- rich vadose zone of the Minford sediments. Due to the low permeability of the vadose zone sediments, contaminants would tend to migrate along discrete pathways - these pathways were described as "dark veins" in previous characterization studies. The tanks in the X-740 unit included TCE and other chlorinated solvents, gasoline and other hydrocarbons polychlorinated biphenyls (PCBs), and other miscellaneous organic compounds. During facility decommissioning, concrete core samples and soil samples were collected. The data indicated contamination beneath the slab foundation and footer of the X-740 facility. Soil samples at depths of 2 feet indicated the presence of organics and PCBs. When the tank floor was broken up on the north side and the concrete and soil had been removed to a depth of 3 feet below the building foundation, a vein of dark soil was uncovered. In addition, VOC compounds were detected in the exposed soil and the fumes in the vicinity of the excavation saturated the respirator canister of the onsite workers. The soil continued to be excavated to a depth of 4 feet below bottom of the concrete sump where two additional veins of discolored soil were discovered while a potential third migration path out of the building along the north wall foundation was also observed. The visually contaminated soil was removed to the boundary, 2 feet from the wall, as per closure plan; however, discolored soil was still visible. The pit was excavated an additional 2 feet and 10 samples were collected. These samples presented contaminants content including TCE. Along the south wall soil was also removed down 2 feet, but the dark soil was still visible and migrating south from the tank wall.

Contaminated soils were removed to a total depth of 6 feet below ground surface. TCE and other contaminants were found in the soil samples, and groundwater samples. In the north side wall sample studies performed in 1993, TCE was identified and quantified at $3400 \mu \mathrm{g} / \mathrm{kg}$ at a pit bottom depth of 6 feet, and a 9' 6' 'distance from west side wall. In 1994 the area was triple washed and excavation was lined. Gravel and concrete were added on top to prevent potential sources of water from contaminating the backfill. The principal contaminant found at depth in the vadose zone and widely detected in the groundwater at this site is TCE. Thus, TCE is the primary constituent of concern for remediation.

\subsection{Review Team Conceptual Model(s) for Soil and Groundwater Contamination in the vicinity of $\mathrm{X}-740$}

\subsection{Conceptual Model Development Process}

One of the first, and most important, activities of the review team was to explicitly develop and articulate clear conceptualizations of site conditions. To be useful, these conceptualizations must be site-specific, represent a reasonable consensus, and describe key attributes of the site to support matching remediation technologies to site needs and/or to assess "technical impracticability." The team distilled the available site information into such an actionable conceptual model which is described below. 


\subsection{Contaminant Hydrology}

Conceptually, the contaminant hydrology of the X-740 area is relatively straightforward (Figure 3a). TCE, a relatively dense industrial solvent, was a primary contaminant released to the subsurface. Contamination from these source(s) penetrated the Minford Silt and Clay Member of the Teays Formation. The water table occurs in the Minford so that the uppermost portion of this unit is partially saturated and the lower part is saturated. As depicted in Figure 3a, contaminant migration in the Minford was predominantly downward. The limited data on the TCE sources and residual contaminant distribution in the Minford near X-740 suggest that releases and spills (e.g. at the former storage tank) entered the Minford and migrated downward forming "dark veins" that were partially removed during facility decommissioning. The vadose data indicate that the contamination is patchy and that many of the Minford samples collected in/near the source zone were below detection limits for TCE. Recent modeling suggests that the releases near X-740 were relatively small ("tens of kilograms" versus the "thousands of kilograms" at the nearby X701B). The limited and patchy residual contaminant levels and the low permeability (hydraulic conductivity approximately 0.1 feet/day) of this formation limit the potential for identifying and implementing Minford-targeted remediation technology.

TCE penetrating the Minford enters into another unconsolidated unit, the Gallia. As described above, the Gallia ranges from 0 to 5 feet thick in the vicinity of the former X740 facility. The Gallia is significantly more permeable than the overlying Minford and the underlying Berea Sandstone. Thus, the Gallia is a primary zone of lateral groundwater and contaminant movement near X-740 (as shown by the roughly horizontal flow lines sketched on Figure 3a). As the primary transmissive zone in the system, the Gallia represents the most practical target for deployment of in situ remediation treatment reagents - despite a limited thickness, injection/extraction remediation strategies focused in this zone would provide maximum lateral impacts with minimal potential risk of failure or adverse collateral impacts. Data from pump tests, geological characterization studies, and conceptual models of the depositional processes, all suggest that the Gallia can be described as a "strongly heterogeneous" zone. This means that much of the flow and transport is through a highly permeable fraction of the Gallia (sand or gravel lenses, open pathways, etc) while relatively stagnant water exists in the remaining fraction.

Due diffusion over time, the TCE contamination currently in the groundwater will reside in both the permeable and less permeable materials within the Gallia, and will have penetrated to a limited extent into the adjacent Minford and Berea (Figure 3b). Remediation technologies will need to treat the permeable zone and have sufficient longevity to treat: a) "back-diffusion" of contamination out of the less permeable zones within the Gallia, b) back diffusion/transport from the Berea, and 3) back diffusion and future source migration from the Minford. In the most recent modeling studies, the effects of the strongly heterogeneous nature of the Gallia on contaminant transport were reasonably well simulated using a dual domain approach, supporting the validity of this conceptual approach. 


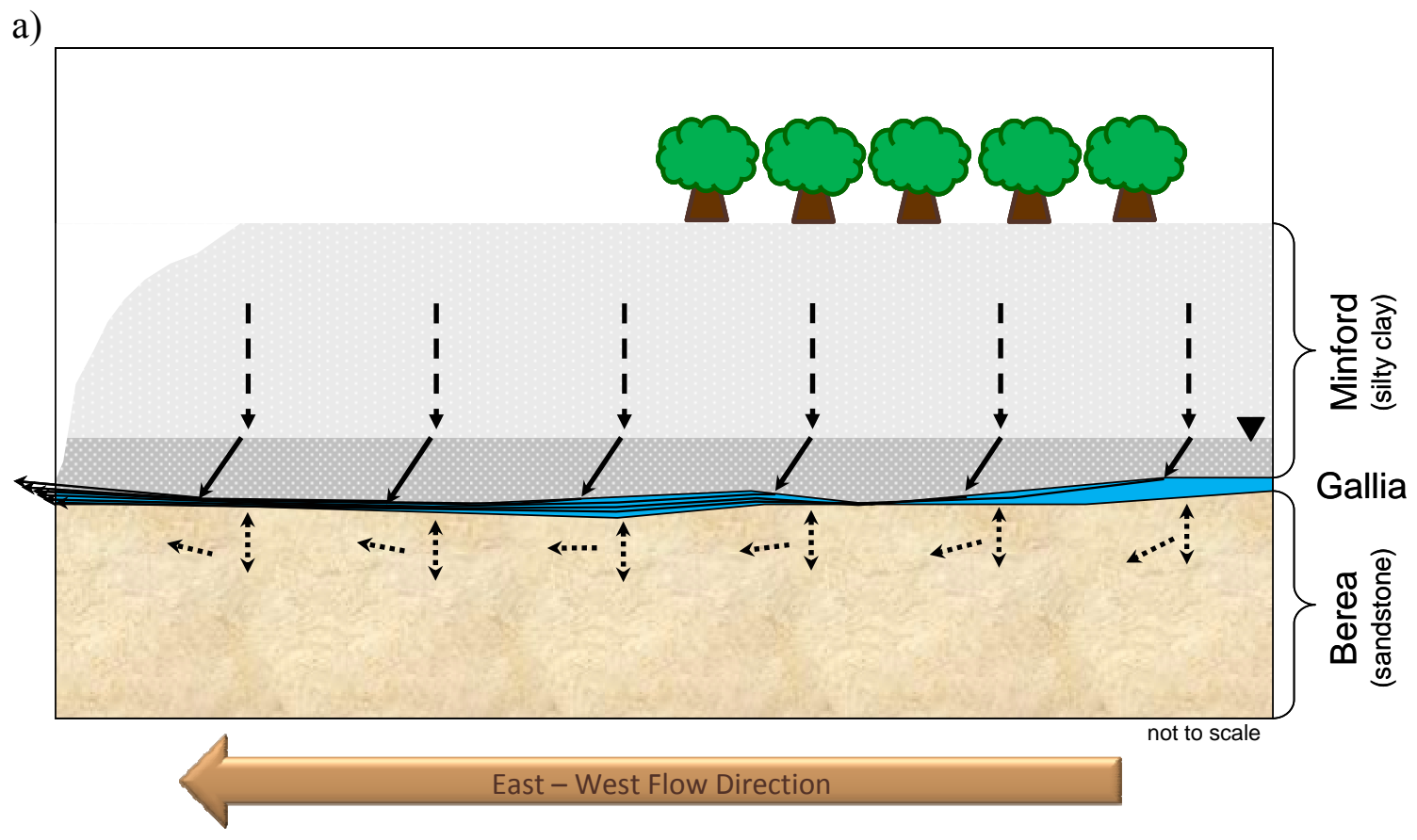

b)

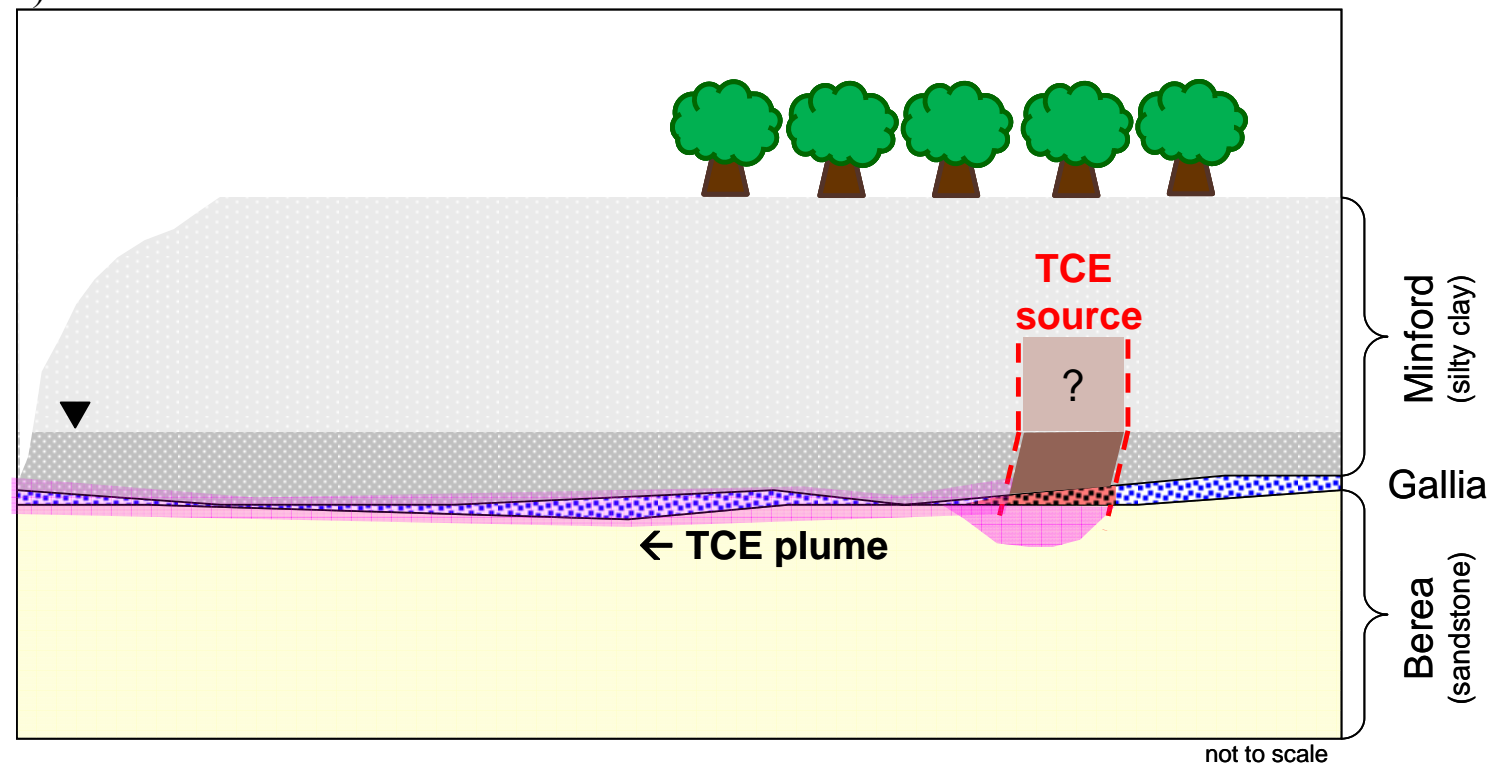

Figure 3. Summary conceptual model for TCE in the soil and groundwater in the vicinity of the former X-740 facility: a) simplified hydrology depicting flow directions and rates;

b) contaminant distribution showing approximate geometry of the source and down gradient treatment targets 
In the X-740 area, groundwater in the Gallia flows west toward site streams and a catch basin ("manhole") and drain system (Figure 4). These hydraulic boundaries collect/drain water from the X-740 plume area. Significantly, the technical review team believes that the catch basin and the associated ("leaky") concrete drain lines play a substantive role in limiting the growth of the plume - these distal drains "stabilize" the plume and provide infrastructure that might be usable as a component in future mitigation strategies. Because of their potential importance, the catch basin and related issues are addressed in more detail in the evaluation below.

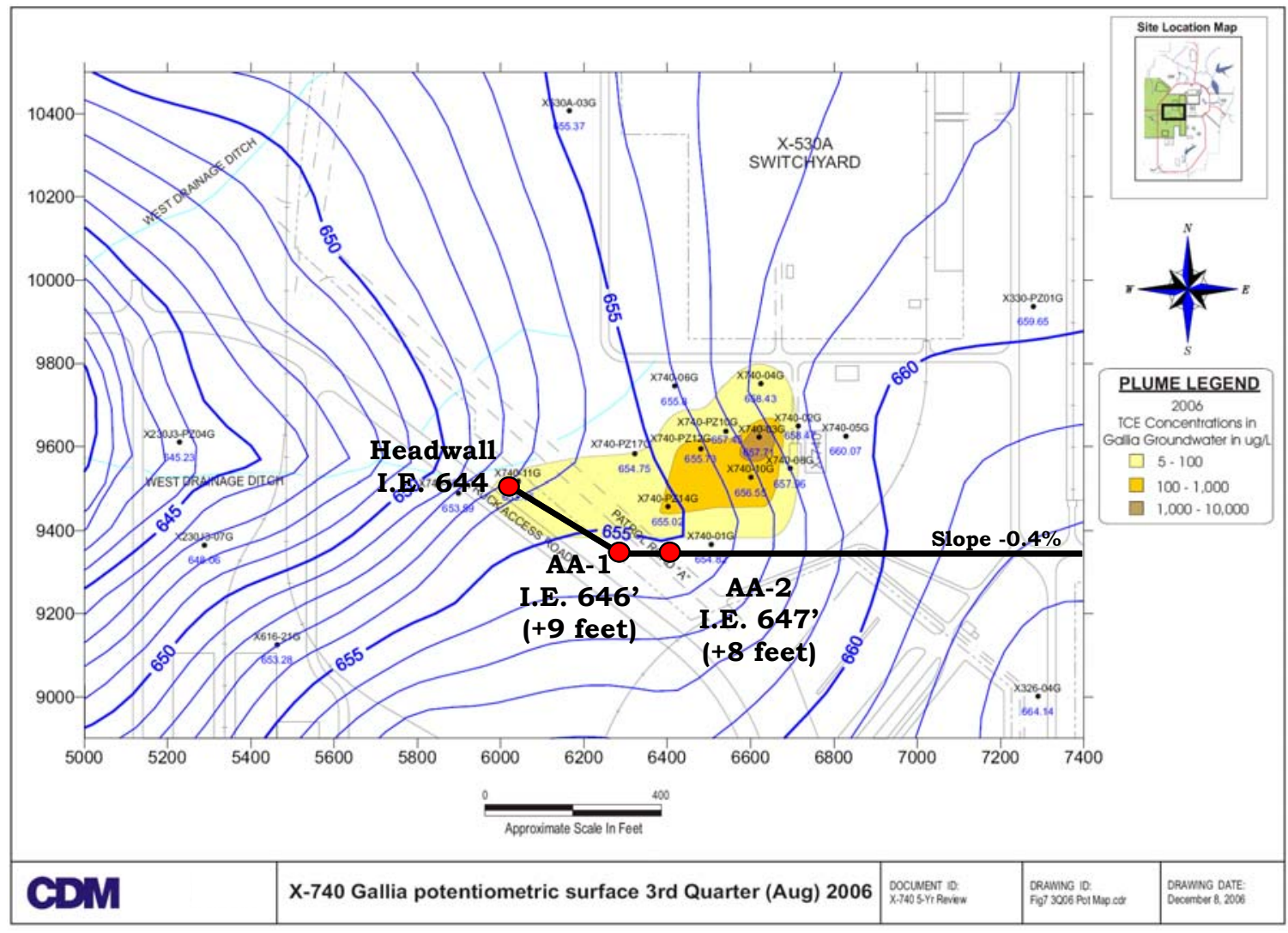

Storm Sewer Reference - Drawing PKS 208-9

Figure 4. Overlay of storm drain system, local streams, and August 2006 potentiometric surface in the Gallia. Elevations (I.E.) of the storm drain lines are provided. Values in the parentheses are the distance below the water table. Note that water flows continuously in the catch basin AA-1 suggesting groundwater baseflow collection. 
The review team noted that water levels in the Gallia fluctuate significantly from season to season. Since the more conductive sediments in the Gallia function as the primary transmissive zone in this area, it provide the primary pathway that propagates the significant seasonal fluctuations in water level throughout the subsurface, and allows the overall hydrologic system to respond to changing boundary conditions. This concept suggests that TCE enters the low permeability (hydraulic conductivity approximately 0.5 feet/day) Berea by diffusion or by flow processes. Diffusion would contaminate a thin veneer of Berea adjacent to the Gallia plume. There are two types of flow drivent processes: 1) resulting from regional flow patterns (depicted in Figure 3a as angled arrows in the Berea) and 2) resulting from seasonal oscillation in water levels (depicted in Figure $3 \mathrm{a}$ as oscillatory vertical arrows into/out of the Berea). In areas where the Gallia is contaminated, this latter process drives contamination into the Berea and then partially flushes it out according to seasonal cycles. Based on the data, TCE has penetrated the upper portion (approximately $10 \mathrm{ft}$ ) of the Berea.

Figure 5 illustrates the nature of the dynamic and complex relationship between the Gallia and the underlying Berea. On this figure, the measured water levels and measured TCE concentrations for two wells (X740-03G in the Gallia and nearby well X740-09B in the Berea) are show over a three year period. The large black arrows connect the seasonal peaks in the hydrograph and measured TCE concentrations from Berea well $\mathrm{X} 740-09 \mathrm{~B}$. In this well, the seasonal peaks in the concentration of groundwater TCE are contemporaneous with high measured water levels.

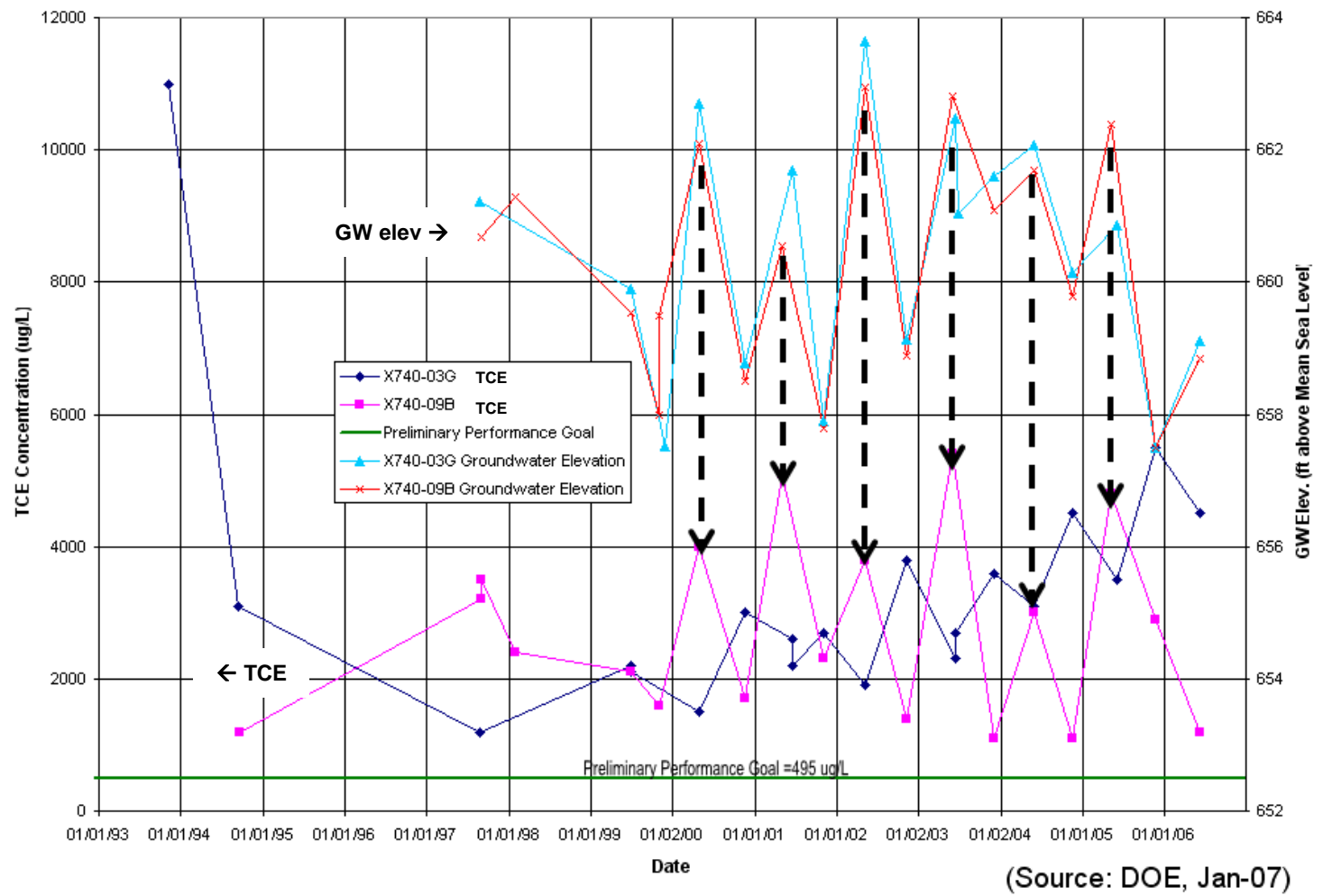

Figure 5. Gallia and Berea hydrographs showing groundwater elevations and TCE concentrations in the Berea illustrating the impact of seasonal water level fluctuations to measured contamination levels for wells in the X-740 source area. 


\subsection{Impact of Conceptual Models on Remedial Strategy}

Consistent with the conceptual understanding of TCE contaminant hydrology at this site, the potential target treatment zones include (Figures $3 a$ and $3 b$ ):

1) vadose zone source area (the small area of partially saturated Minford overlying the plume centroid),

2) groundwater source area (high concentration plume core, $>1000 \mu \mathrm{g} / \mathrm{L} \mathrm{TCE}$, in the Gallia),

3) downgradient plume (50 to $1000 \mu \mathrm{g} / \mathrm{L}$ TCE in the Gallia)

4) contaminant in the Berea

For the vadose zone, the nature of the release and transport and the sequence of partial removal actions resulted in a patchy distribution of TCE. While the putative source area appears to be small, TCE has proven difficult to find/target in the vadose zone. The low permeability in the vadose zone limits the ability to remove contaminants (e.g., with SVE) or to deliver treatment amendments. Due to the limited areal extent and potentially small amount of residual TCE currently in the source area vadose zone, enhancements such as thermal technologies do not appear to be justified.

Of these target zones, the two Gallia treatment targets (2 and 3) are most accessible and amenable to treatment. The presence of contaminated low permeability zones above (Minford), below (Berea) and within the Gallia is an overarching challenge that strongly impacts the selection and design of potential remediation technologies. The slow release from less permeable Gallia sediments combined with inputs from contaminated portions of the "sandwiching" layers represent a long term source of TCE that can re-contaminate the Gallia in the future. Therefore, technologies that effectively treat the permeable portions of the Gallia, but do not leave residual treatment capacity in the system are unlikely to achieve long term remedial action objectives. Any technology selected for the groundwater source area should consider and address future TCE inputs from the Minford. Further, due to the dynamic relationship between the Gallia and the underlying Berea, technologies that reduce aqueous concentrations in the Gallia to relatively low level for an extended timeframe, should result in a steady reduction of the deeper zone concentrations and "shrinking" of the Berea plume. Finally, the distal catch basin and the associated piping appear to limit plume growth and are predicted to collect the groundwater from much of the TCE plume area.

The description above is generally consistent with the prevailing site conceptual model for the X-740 area and the conceptual model used by CDM in their recent evaluation of remedial technology alternatives. The technical review panel refined the description with more emphasis on the control exerted by the distal drain features such as the catch basin and with more emphasis on the potential for dynamic transfer of Gallia contamination to/from the Berea Sandstone. The panel consensus was that the current conceptual model is reasonable particularly when supplemented by the suggested refinements. 


\subsection{Recent Technology Selection Efforts}

The following briefly summarizes the major stages of groundwater remediation that have been performed to date for the X-740 facility at Portsmouth:

o ...1994 - Facility operated and then decommissioned. During building removal, contamination (“dark veins") observed and vapors detected in work area. Partial removal (e.g., 4 feet), rinsing and lining of excavation.

o 1999 - "Phytoremediation" implemented at X-740 to address contamination in the groundwater. The DOE planted poplar trees over 2.6 acres of the groundwater plume. Monitored for 10 years; did not meet remedial objectives

o 2008 - Alternative remedial strategy (in situ chemical oxidation) initiated. Three treatment phases of chemical oxidation were completed; did not meet remedial objectives

o 2009 - OEPA requested an updated evaluation of technology alternatives. CDM is completing the evaluation and has drafted a report.

The final item in the historical listing above is of particular importance to our review team process for X-740. The DOE review team was provided a working copy of the CDM technology alternatives evaluation draft report. In this document, CDM evaluated a variety of technologies and assessed potential viability using traditional regulatory, engineering and cost metrics. The current alternatives evaluation extends the original Corrective Action Study / Corrective Measures Study (CAS/CMS) that was performed for this site (DOE, 1998).

One of the key features of the CDM report was the delineation of two target zones for which technologies could be customized and optimized (Figure 6). We strongly support this conceptualization. As we discuss in a later section, the matching of technology to the specific site conditions and how these conditions change through time is central to developing a reasonable environmental remediation strategy that will maximize progress toward remedial action objectives (RAOs). The matching process endorsed by our review team is graphically depicted in a simplified form in Figure 7. This type of matching process encourages innovative and creative combinations of technologies, encourages planning for transitioning technologies as conditions improve, and encourages efficiency and effectiveness by focusing selected technologies toward their strengths. For example, this paradigm encourages early use of aggressive technologies (e.g., physical removal, chemical oxidation, thermally enhanced extraction) in high concentration source areas and use of lower energy technologies (e.g., passive in situ methods) in more dilute portions of the plume and at later stages in the remediation process. 


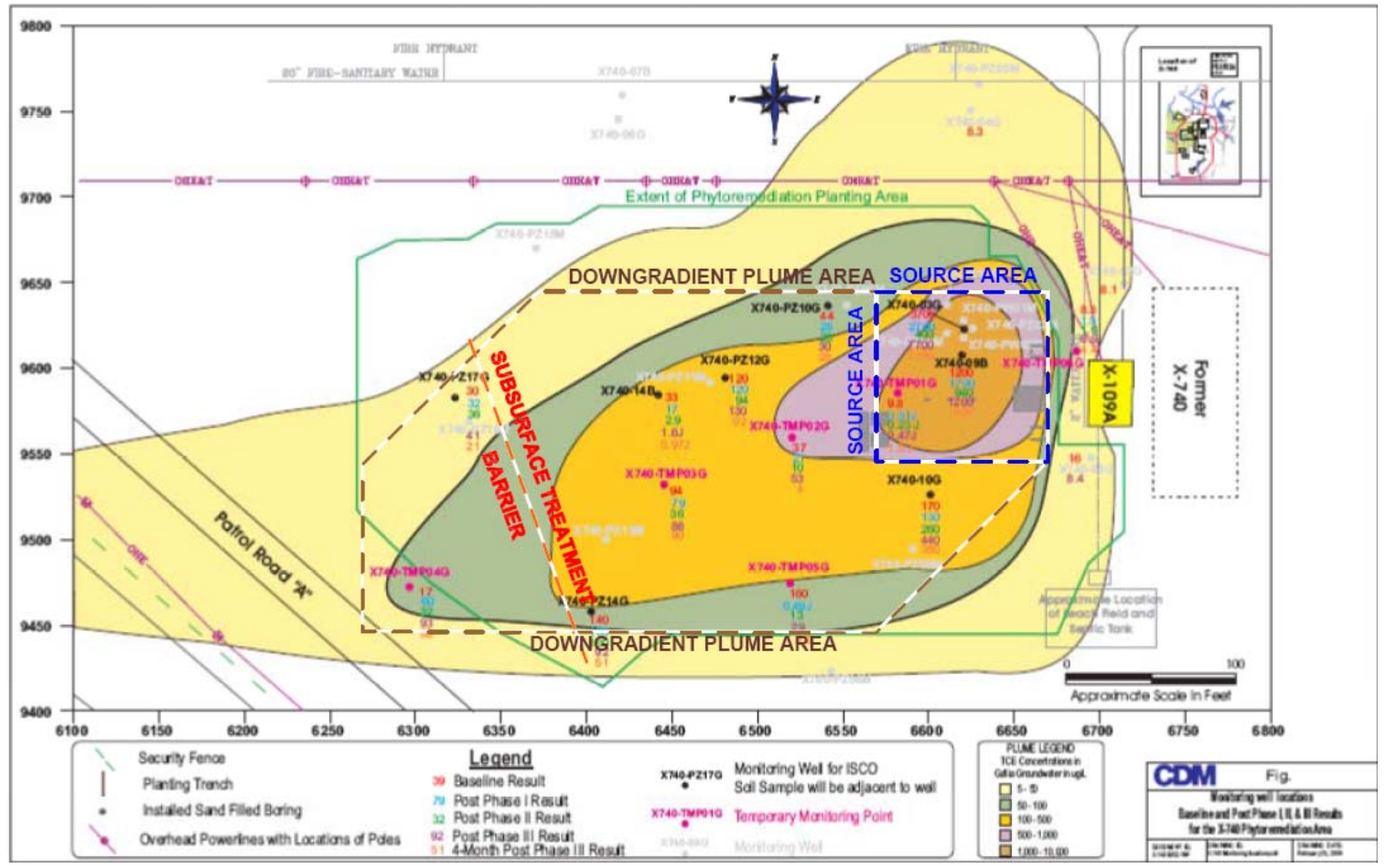

Figure 6. Plan view map depicting source and down gradient treatment targets.

These areas were defined by CDM (draft alternatives report) and represent the zones where groundwater in the Gallia contains $>1000 \mu \mathrm{g} / \mathrm{L}$ and 50 to $1000 \mu \mathrm{g} / \mathrm{L}$, respectively. Designating target zones in this way is a valuable tool in matching technologies to site conditions and in optimizing treatment technology selection. The overlying Minford contains TCE contamination within the isolated portions of the designated source area and the uppermost portion of the underlying Berea also contains TCE contamination. 


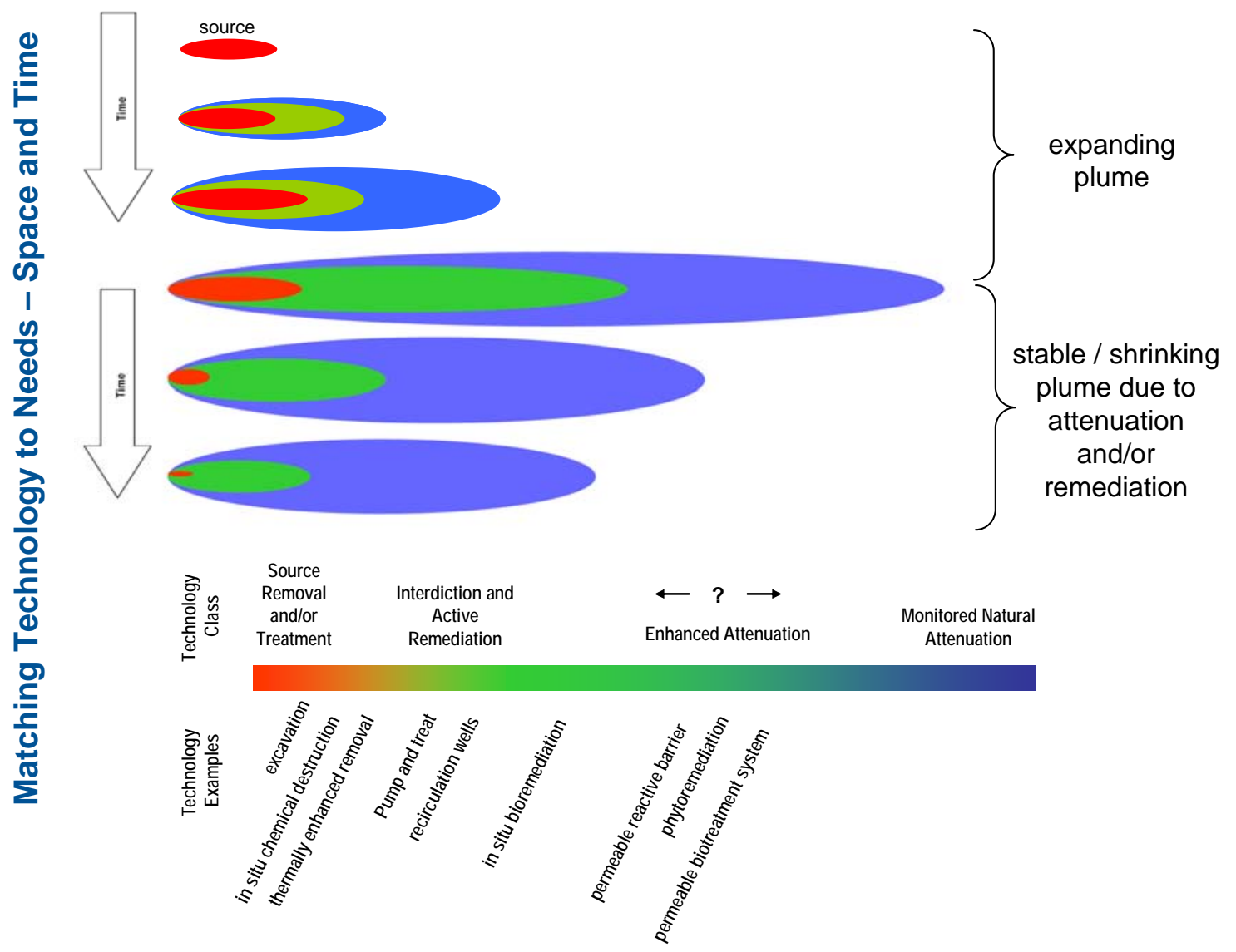

Figure 7. Image showing the lifecycle of a contaminant plume and a continuum of possible technologies matched to different target zone. 
The CDM alternatives evaluation was performed sequentially as a series of tiered evaluations that graded from screening efforts to more detailed and formal assessments of specific evaluation criteria. Each of these is summarized below.

Preliminary screening: The CDM evaluation team first identified "General Response Actions" (GRAs) that "singly, or in combination," might satisfy RAOs. The general response categories were "no action, institutional controls, containment, ex situ treatment, and in situ treatment." The CDM team focused primarily on containment and in situ treatment options as the most promising technologies for moving this site toward RAOs the remaining GRAs were described as "well evaluated" in the earlier CAS/CMS and were determined to be either no responsive (e.g., no action), or of limited effectiveness (e.g., ex-situ treatment). In this initial technology screening, process options and technology types were eliminated from consideration if they are not technically feasible due to a lack of compatibility with site characteristics (e.g., physical features of the site and chemical characteristics of the media of concern), or if the technology has not been proven to effectively address the COCs. These screening criteria were applied based on published information, experience with the technologies and process options, knowledge of site characteristics, and engineering judgment.

In the preliminary screening phase, the CDM team "retained" potentially viable technologies for more detailed evaluation and did "not retain" technologies that were deemed ineffective, inefficient, or undeployable. Several containment technologies were retained (physical barrier walls and hydraulic containment) while caps and vegetative covers were not.

Under the in situ treatment GRA, three remedial technology types were evaluated: physical/chemical, biological, and thermal. Additionally, delivery methods were considered because access and delivery is often a major determinant of remediation performance, particularly for a challenging hydrogeologic setting like X-740. The two retained physical/chemical treatment options were chemical oxidation and permeable reactive barriers. The physical/chemical process options not retained were air sparging, dual phase extraction (DPE), circulating wells, surfactant enhanced aquifer remediation (SEAR), and in-well air stripping. Four process options were identified under biological treatment: natural attenuation, anaerobic bioremediation, phytoremediation, and biosparging. All of these options were retained except for biosparging. Thermal treatment was retained. The in situ access and delivery methods identified include: direct push technology (DPT), vertical injection wells, recirculation, trenches, horizontal injection wells, hydraulic fracturing, and infiltration. All of these were retained except for infiltration.

Alternative Screening: Each of the retained alternatives was further described by generating a hypothetical deployment for each. For purposes of this intermediate screening, these hypothetical deployment descriptions included an assumed amendment and required volumes, one or more deployment scenarios and industry norms for deployment costs, and general expectations for effectiveness in terms of reducing the mobility, toxicity or volume of contaminant. The results from this intermediate level of 
evaluation were used as a gate that passed technologies on to a detailed analysis. As shown below, several technologies were retained for detailed analysis, while two technologies (phytoremediation and pump-and-treat) were not retained. The retained technologies from this alternatives screening were:

Alternative 1 - Hydraulic Fracturing with EHC® Injection 1a - Source Area EHC® Injection $1 \mathrm{~b}$ - Downgradient Plume EHC ${ }^{\circ}$ Injection

Alternative 2 - Enhanced Anaerobic Bioremediation $2 \mathrm{a}$ - Source Area EAB with Injection Wells $2 b$ - Downgradient Plume EAB with DPT Points $2 \mathrm{c}$ - Downgradient Plume EAB with Injection Wells

Alternative 3 - In situ Chemical Oxidation $3 \mathrm{a}$ - Source Area ISCO with Injection Wells $3 b$ - Downgradient Plume ISCO with DPT Points $3 \mathrm{c}$ - Downgradient Plume ISCO with Injection Wells Alternative 4 - Electric Resistance Heating (Source Only) Alternative 5 - Reactive Barriers (Downgradient Only) $5 \mathrm{a}-$ Permeable Reactive Barriers $5 b$ - Biobarriers

As we describe in the Technical Evaluation Section (3.0) below, our review team found the CDM review process and screening/evaluation sequence to be generally credible and well performed. The screening assessment of our review team, however, diverges somewhat from the CDM results. For example, our team concluded that: 1) the CDM assessment of fracturing (particularly in the Berea) may not adequately capture the technical and cost risks and uncertainties, and 2) some of the selected amendments (e.g., lactate for bioremediation and any of the oxidants) may not be well suited to the required diffusion controlled long-timeframe for X-740. In a few cases, the differences in approaches between the CDM team and our review team impact the ultimate configuration and cost of potential remedial strategies. These are discussed further below.

Detailed Analysis of Alternatives: The CDM technology evaluation culminates in a relatively detailed evaluation of each of the alternatives retained in the previous Alternatives Evaluation stage. The evaluation criteria included: protection of human health and the environment, compliance with applicable or relevant and appropriate requirements (ARARs), long term effectiveness, reduction of mobility, toxicity or volume, short term effectiveness, implementability, effects on current remedial action, and cost. These evaluation criteria are generally reasonable and helpful in decisionmaking. One exception might be the criterion related to effects on current remedial action - this is evaluated in terms of compatibility with and preservation of the existing stand of hybrid poplars. The consensus of our review team is that the hybrid poplars are having only a limited impact on the contaminant plumes (providing some infiltration reduction but little contaminant extraction or destruction), thus the preservation of this infrastructure is not a significant evaluation criteria. 
The detailed evaluation was not final during the technical review, but appeared to be leaning toward a few of the options, notably bioremediation using EHC and fracture deployment. Our review team supports the use of bioremediation using a long lived electron donor (EHC is a good exemplar of a long lived organic reagent - this particular material being enhanced with zero valent iron). Unfortunately, because it is a solid, this material would require a fracture type of installation that has significant technical and cost risk/uncertainty.

The CDM report took significant strides toward identifying and matching technologies to the source zone and the plume zone. In some cases, however, costs and decisions were skewed by assuming that the same technology would be used in both areas. Additionally, as a result of the poor performance of the previous remediation activities and challenging conditions at the site, DOE has expressed concern about the viability of a single technology to move this site to RAOs in a reasonable and timely manner. Our team provides supplementary technical information, evaluation, and recommendations and addresses these topics below.

\subsection{Technical Evaluation}

\subsection{Review Team Statement on Technical Impracticability}

In a concise form, the review team objectives were:

o Review and comment on site history, the X-740 Work Plan and performance information for the recent ISCO remedy, the recent OEPA letter requesting an evaluation of alternatives and contingencies, etc.

o Determine the feasibility of declaring Technical Impracticability

o Provide recommendations for other cost effective technologies that could be considered / implemented. (Potential for success, risks, robustness to uncertainties...)

After the historical and technology performance review and substantive follow-on discussion, the consensus of the review team was that current information does not support a determination of technical impracticability. Despite the challenging site conditions and the failure of the previous two remediation campaigns to adequately move the site toward RAOs, the review team was unanimous in the conclusion that an effective combination of cost effective technologies can be identified. Further, the team expressed optimism that RAOs can be achieved if realistic timeframes are accepted by all parties.

The key to implementing a creative and effective solution will be explicit and careful matching of technologies to the unique characteristics (i.e., opportunities) at the site and by separately targeting actions for the source and plume zones. The technologies used to date exemplify the need for such matching - these technologies had positive impacts, but were relatively poorly matched to site conditions. The depth to groundwater was a fundamental physical limit for the phytoremediation system - available suction lift under natural conditions is not sufficient to effectively draw up groundwater, even with the installed sand stacks. Thus, the phytoremediation served primarily as a recharge 
reduction system rather than an effective contaminant removal and/or destruction system. Similarly, the recent ISCO, using modified Fenton's Reagent, while destroying the contaminant that it contacted, would have limited long-term benefits toward RAOs because the lifetime of oxidant used was too short to address the bulk of the remaining contaminant which is being slowly released from fine grained zones into actively flowing portions of the Gallia. Thus, both previous technology applications, phytoremediation and ISCO, were somewhat misfit to this particular site. The performance of these remediation technologies at X-740 and the eventual determination by OEPA and DOE that these technologies were ineffective is both cautionary and instructive. Because of the issues described above, the poor performances to date are not necessary and sufficient documentation to justify technical impracticability. Instead, the site is at a critical juncture in which DOE, the contractor and OEPA have an opportunity to put the lessons to use to develop a strategy that has a significant potential for success.

\subsection{Review Team Technical Evaluation Process}

The historical performance of phytoremediation and oxidant injection, combined with the recent on-site efforts to evaluate potential remediation opportunities for the X-740 TCE plume provided a strong basis for the efforts of the technical review team. These resources allowed the team to focus on refinement of the conceptualization of the site and how these impact the performance and risks of the various evaluated technology classes.

The steps in the technical review processes are shown in the information box below:

\section{DOE Review Team for the X-740 Groundwater Plume}

Structured review process

o Validate objectives and obtain input from DOE, OEPA and site contractor

o Review historical facility information and site data

o Develop the key elements of a site conceptual model to inform the review and discuss the issue of "Technical Impracticability"

o Review the recent CDM draft X-740 Alternative Technology Report (evaluation criteria, ratings, and description of proposed implementation for preferred technologies)

o Develop team consensus on the various technology classes (viability, key information to inform alternatives evaluation, potential viability, risks, etc.)

o Summarize results into recommendations and example technology combinations for consideration 
The review team determined that the draft X-740 Alternative Technology Report was generally credible and based on reasonable ranking criteria. While our review team did independently develop a number of specific recommendations, issues, approaches, and alternatives for the Portsmouth team of DOE, CDM and OEPA to consider, our team members felt that generating a separate-comprehensive alternatives evaluation did not represent the most effective format for communicating the consensus results. As shown in the steps listed above, the panel instead used the existing evaluation and a base and documented key technical factors, considerations and recommendations, and the assessments specifically requested in the Portsmouth Technical Assistance Request (e.g., performance of the oxidant campaigns, appropriateness of Technical Impracticability for this site, etc.) in a manner organized to dovetail with the draft X-740 Alternative Technology Report. Thus, the team advocates that the two efforts and the associated reports be used in partnership, and specifically urges strong consideration of the technical review team's recommendations as the alternative technology evaluation is completed.

Key points that guided the review team evaluation: Careful delineation and refinement of target treatment zones, along with the character of the various target zones, were considered to be pivotal to the technology evaluations and development of proposed implementation strategies. The team emphasized the potential benefits of decoupling the technology decision for the source area and the down gradient plume area. The process of matching and optimizing technologies based on the different conditions throughout the source/plume maximizes the likelihood of success, potentially reduces cost, and results in the opportunity for a combined remedy - for example, development of structured geochemical zones in which the degradation and attenuation mechanisms exhibit synergy as water moves from the source area to the down gradient area. The team also recognized the challenges associated with treatment of the low permeability Minford and Berea, and the low permeability materials within the Gallia - this necessitates that treatment technologies be selected that maximize treatment longevity while exhibiting acceptable deployability. Further, the team focused the technology evaluations to target the primary transmissive zone (e.g., the Gallia) and recommended less focus on the active remediation of the low permeability zones - the vadose and saturated portions of the clayey Minford and the upper portion of the Berea Sandstone.

\subsection{Review Team Technical Evaluation Results}

\section{Containment}

Containment is performed by constructing physical barriers, controlling the quantity and flowpath of water, and/or through the strategic application of materials that chemically sequester or partition contaminants. These approaches do not remove or destroy contaminants. Instead they keep the contaminants in place and extend the release over a longer timeframe (but at a reduced flux). If strategically used, in combination with technologies that remove and destroy the TCE, containment may help achieve specific remedial process goals (e.g., reduced target concentrations or fluxes that are compatible with bioremediation or other companion technologies). In general, our review team concurs with the CDM screening in which caps and walls were not retained. We also concur with the CDM screening determination in which traditional hydraulic containment 
(i.e., pump and treat) was not preferred - as an alternative, we describe below an innovative containment concept in which clean water is collected and diverted around the contaminated area.

The simplest isolation and immobilization concept is a surface cap. An extensive capping effort would have a limited impact on the plume because: 1) the Minford is relatively low permeability and 2) the contamination in the Minford appears to be limited and patchy and the lower portion of the formation that has been penetrated by diffusive processes from the underlying contaminated Gallia plume. Capping would tend to extend the timeframe of groundwater treatment, increase the diffusive penetration of contaminants into the lower Minford, and is unlikely to substantively impact groundwater concentrations. A variety of other physical barriers, such as subsurface walls (slurry or sheet piling), are also feasible but would be costly and have a performance (i.e., minimal benefit) similar to capping. Chemical amendments that sequester contaminants by partitioning mechanisms have the potential to be useful, if they are used in combination with, and are synergistic with, contaminant destruction processes. The most common exemplar of sequestering/partitioning is the use of hydrophobic bioremediation amendments (e.g., vegetable oil, EHC, etc.). Because partitioning is a secondary "benefit" of the primary deployment, these amendments will be addressed in the bioremediation section below.

Passive hydraulic manipulation is a potentially effective and underutilized concept for isolating sources and reducing the flux and release of contaminants. In this case, "clean" water would be intercepted upgradient and passively diverted downgradient, reducing the flow of water through the source and plume. The result would be a reduction in contaminant release - each gallon of diverted clean water results in a concomitant reduction in the release of contaminated water. At some sites, this is a viable and attractive option because the flux-reduction benefits are realized without the need to treat any of the "clean" water being diverted. The hydrogeologic and engineering information provided for the X-740 site suggests a site specific opportunity for passive hydraulic containment. The Portsmouth engineering diagrams depict many large drain lines in subsurface in the vicinity of X-740 and that the elevation of these lines is often below the water table - in some cases, drain lines are located at depths that are in or near the Gallia and the piezometric surface in the Gallia is nominally 8 to 9 feet above the elevation of these drain lines. This infrastructure has the potential to serve, opportunistically, to support site remediation strategy. Specifically, our team identified that the catch basin (manhole) A-8 is located upgradient of the site. According to the engineering drawings, this catch basin is configured to accept an additional drain line and the system elevation may support installing a passive groundwater drain at minimal cost. The baseline and hypothetical passive drain piezometric surfaces in the Gallia are depicted in Figure 8, along with the location of catch basin A-8. Installation of the passive drain (Figure $8 \mathrm{~b}$ ) would reduce water flow through the contaminated area (exemplified by the more widely space contour lines), reduce the contaminant flux to downgradient stream and catch basin discharge boundaries, reduce the overall head (pressure) in the Gallia, and damp seasonal fluctuations in Gallia head. The "extracted" water would not contain TCE from the X740 source or plume and should not require surface treatment. Thus, an upgradient 
passive drain provides several potentially significant benefits, but the diversion of the water would also partially isolate and "stagnate" the plume in place and could extend the remediation timeframe. As a result, this strategy would be most useful if applied in combination with a primary treatment technology that would benefit from the reduced influx of upgradient water and the longer time that the contaminants would spend in the source zone and plume. An important example of such a primary technology is anaerobic bioremediation. The reduced inflow of water from upgradient would reduce the inflow of oxygen and other competing electron acceptors, would reduce the potential for flushing treatment reagent out of the target zone, and would allow more time for the induced bioremediation to degrade contaminants.

In summary, containment technology has potential value at the $\mathrm{X}-740$ site. In general, this potential is limited if containment is used alone. Our review team supports the CDM alternatives evaluation report determinations that eliminated specific types of containment such as caps and walls and discouraged pump-and-treat. As described above, the review team urges the Portsmouth team to consider an upgradient passive drain strategy if it would couple synergistically with a primary treatment technology such as in situ bioremediation. This passive upgradient drain strategy was rated as viable and conditionally recommended. 
a)

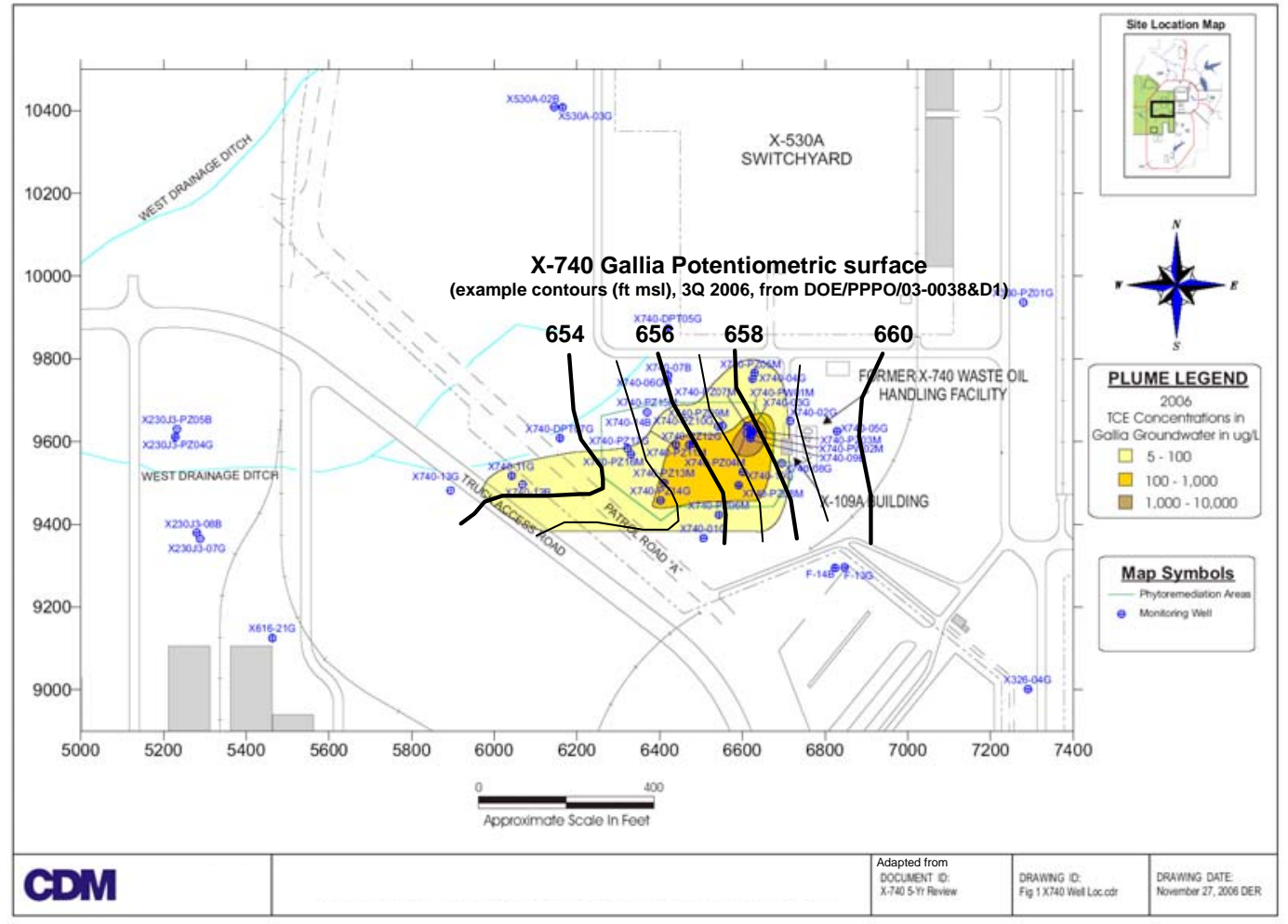

b)

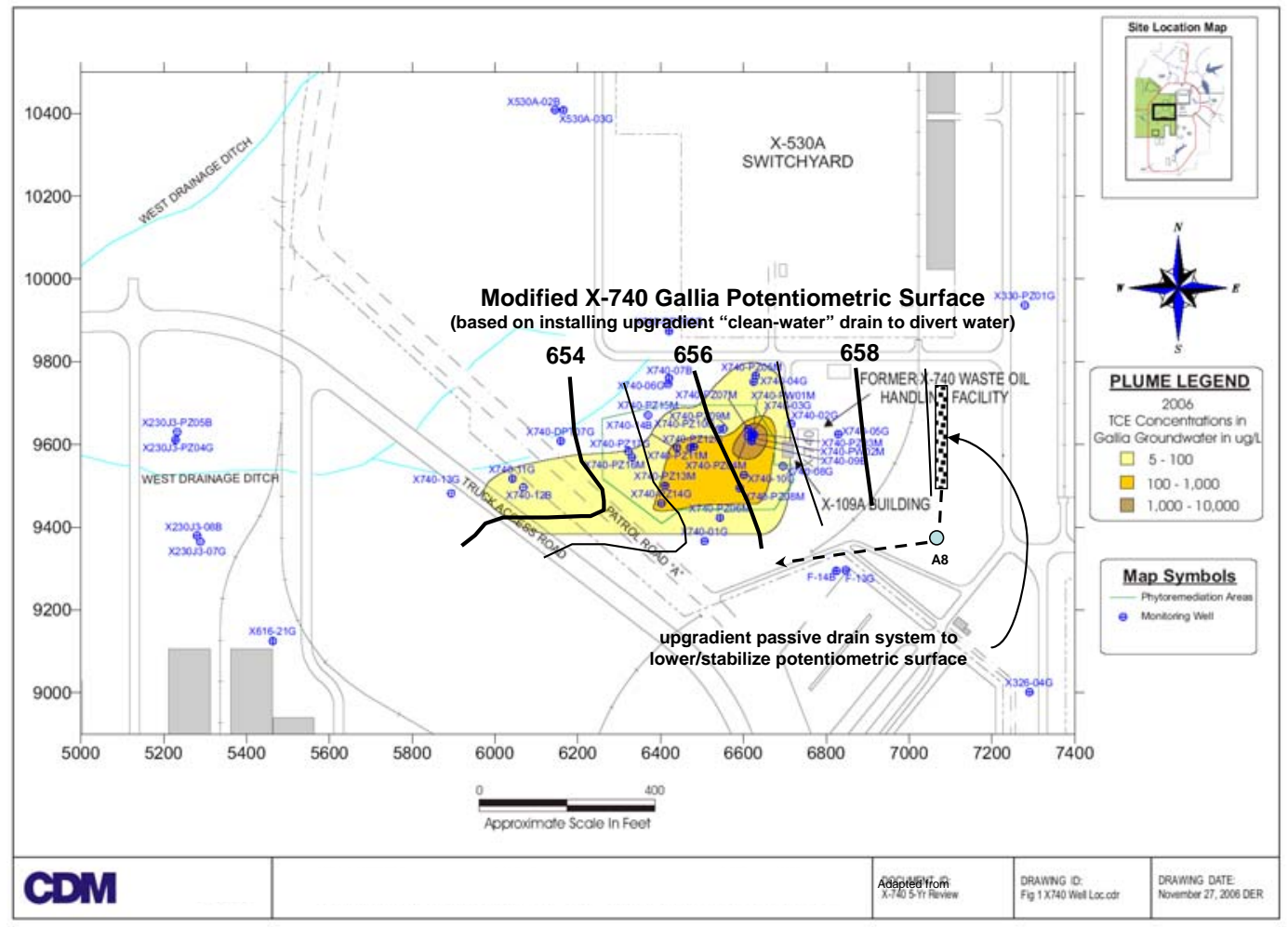

Figure 8. Piezometric surface in the Gallia Formation near X-740. a) "Baseline" and b) with a hypothetical upgradient passive drain 


\section{In Situ Chemical Treatment}

In situ chemical treatment uses reactive amendments, typically oxidants, to destroy contaminants in the target zone. In situ chemical oxidation, or ISCO, is an important emerging technology that has proven to be both prudent and effective for cleanup of appropriate sites (EPA, 1999). Data from ISCO case studies provide a general framework for identifying promising sites and for optimizing design and implementation. This framework has three major elements: 1) confirming appropriate target contaminant mass / concentration, 2) matching of oxidant chemistry and longevity to site conceptual model, and 3) developing a practical access and delivery method for site conditions and target contaminant geometry. Each of these elements is briefly discussed below.

Appropriate applications of ISCO generally target source areas with relatively high contaminant concentrations (e.g., 1,000 to 50,000 $\mu \mathrm{g}$ TCE /L) and some residual NAPL ISCO is relatively ineffective for treating large DNAPL pools due to limited contact and relatively ineffective for lower concentrations because dissolved contaminant can be displaced without interacting with the oxidant. For X-740, these rules of thumb suggest that ISCO is potentially applicable to the source zone, but is poorly matched to the downgradient plume.

There are a number of available oxidants, each having a slightly different profile of reactivity, longevity and deployability, and each having identifiable advantages and disadvantages. Common oxidants include:

o hydrogen peroxide (highly reactive liquid reagent, often activated with reduced iron for a "modified Fenton's" reaction, reformulation with other chemicals to stabilize peroxide has been successful at some sites - relatively short lifetime in all cases, even if stabilized),

0 permanganate (moderately reactive reagent that can be applied as a liquid or blended in as a solid, requires minimal activation, generates treated water that is pink in color, moderate lifetime),

0 persulfate (moderately reactive reagent that can be applied as a liquid or blended in as a solid, typically requires chemical or thermal activation, moderate lifetime).

For deployments that use liquid injection for deployment, none of the oxidants is expected to be viable for X-740. The conceptual model for X-740 suggests that only a small fraction of the subsurface is effectively contacted by injected liquids. Injected oxidants would treat contaminants in the preferential flowpaths, but would provide little or no treatment for the relatively large portion of the contaminant mass in the remainder of the source area. This problem would be particularly significant for peroxide based ISCO, but also applies to liquid permanganate and persulfate - the "moderate" lifetimes of these reagents would be insufficient to provide the required "years" or "decades" of treatment capacity indicated by the conceptual model, even if many re-injections were planned. Furthermore, past work at X-740 indicates that the pressurized injections often used for ISCO would likely result in undesired impacts such as "daylighting" and other adverse site conditions. 
While liquid based ISCO does not appear appropriate for X-740, the data suggest that ISCO may be viable if applied in the source zone using physical blending of solid amendment such as granular permanganate. Notably, this deployment concept is similar to that already being used at Portsmouth to treat the source zone of the nearby X-701B plume. In this scenario, the low permeability Minford, containing patchy "veins" of contamination within the vadose zone and shallow groundwater, along with the Gallia and upper Berea would be treated in place using large augers or blending tools with granular oxidant added to treat the contaminant. This process would require significant infrastructure and investment and would face many challenges (e.g., effective mixing of clayey Minford sediments). Nonetheless, blending soils with treatment reagent(s) would improve access to the contaminants that are currently held in low permeability materials and accelerate the overall treatment, relaxing the requirement for reagent longevity. Importantly, ISCO technologies require significant infrastructure and highly reactive chemicals resulting in collateral environmental impacts (resource/energy use, geochemical and subsurface ecology impacts, etc.) that may reduce the overall lifecycle benefit associated with local reduction in TCE concentration.

As noted above, the review team determined that the potential use of ISCO at X-740 should only be considered for the source area, using blending of solid reagent(s), and ISCO would not be appropriate for treatment of dissolved phase contamination in the down gradient plume. A separate strategy would be required to treat contamination down gradient of the source. Although ISCO treatment targeting the source zone might be effective, the high cost of implementation would be a significant disadvantage for this technology when compared with other viable alternatives. The team consensus is that an ISCO treatment using blending of granular reagent(s) is potentially viable but not recommended for implementation at X-740 due to the relatively small mass of residual NAPL in the source zone (e.g., the TCE associated with X-740 is estimated to be $<0.001$ of the quantity at X-701B where oxidant blending was selected and is currently underway), the limited plume size and low risks, and the relatively high costs and potential collateral impacts of implementation.

\section{In Situ Thermal Treatment}

Thermal treatments are used to raise the subsurface temperature to enhance the transfer of residual volatile contamination from slow release sources (e.g., NAPL pools or fine grained sediments) into mobile aqueous and gas phases. These mobile phases can then be pumped from the subsurface for aboveground treatment and disposal. There are several types of commercially available thermal treatments including electrical resistive heating and conductive heating; these have been successfully used to treat residual NAPL contamination. One disadvantage of thermal heating technologies as a class is that they require a large initial capital investment in large-scale process equipment such as blowers, oil-water separators, air stripping towers, condensers, and activated carbon beds. Importantly, thermal technologies require significant infrastructure and large amounts of energy resulting in collateral environmental impacts (resource use, carbon footprint, etc.) that may reduce the overall lifecycle benefit associated with local reduction in TCE concentration. 
The use of thermal treatment at X-740 would only be applicable to the source area and would not be appropriate for treatment of dissolved phase contamination in the down gradient plume. A separate strategy would be required to treat contamination down gradient of the source. Thermal treatment targeting the Minford would be challenging due to the low permeability, but appears feasible. However, the high cost of implementation and the large amount of infrastructure required for treatment of a small area are significant disadvantages for this technology when compared with other viable alternatives.

The team consensus is that thermal treatments are potentially viable but not recommended for implementation at X-740 due to the relatively small mass of residual NAPL in the source zone, the limited plume size and low risks, and the relatively high cost and potential collateral impacts of implementation.

\section{Bioremediation}

There are several general requirements for developing sustainable bioremediation (i.e., a long-term treatment zone) within the flowpath of a contaminant plume. For chlorinated solvents, these typically include: 1) creation of geochemical conditions favorable to the desired reactions (i.e., proper $\mathrm{pH}$, low eH, sufficient macronutrients, low levels of competing electron acceptors, etc.); 2) sustainable sources of substrate hydrogen and hydrogen precursors; 3 ) documentation and maintenance of organisms that are capable of degrading the target contaminants to nontoxic products (adding these if necessary).

The most common and fastest degradation pathway for TCE is reductive dechlorination. Reductive dechlorination is an anaerobic process in which the chlorinated compounds serve as the terminal electron acceptors (Borden, 2006), as opposed to oxygen, which is the terminal electron acceptor during aerobic respiration. The dehalogenation process involves removing a chlorine atom from the alkene molecule, and replacing it with a hydrogen atom. A carbon source addition enhances reductive dechlorination efficiency by providing the bacteria with a carbon source that is required for macromolecule production, and an electron donor that is required for energy production. Lack of suitable carbon sources and electron donors is often the limiting factor for biodegradation in formations below the root zone.

The sequence of "rapid" degradation reactions traditionally documented for chlorinated compounds, starting with TCE, is:

$\mathrm{TCE} \rightarrow \mathrm{c}-\mathrm{DCE} \rightarrow \mathrm{VC} \rightarrow$ Ethene $\rightarrow$ Ethane $\rightarrow \rightarrow$ Carbon dioxide and Water ---anaerobic zone--|--transition--|-----------aerobic zone -------------------

Note that other reactions also occur such as cometabolism of TCE (relatively slow) and oxidation and cometabilism of cDCE (moderate rates) and oxidation of VC (fast).

In the reductive dechlorination process, microorganisms replace chlorine atoms with hydrogen, forming more reduced products. In this process, where trichloroethene (TCE), is subsequently reduced to 1,2-cis-dichloroethene (c-DCE), vinyl chloride (VC), and 
eventually to, the non-toxic end products, ethene and ethane. Highly chlorinated compounds (i.e. TCE) are more susceptible to reductive dechlorination than less chlorinated compounds (i.e. VC) because they are more oxidized. Therefore, microorganisms that carry out the conversion of TCE to cis-DCE are relatively common and can survive in a variety of environments. The key organisms that can perform the complete anaerobic conversion of chlorinated ethenes to ethane are Dehalococcoides ethenogenes or DHC. This species requires strongly reducing, methanogenic conditions and circumneutral $\mathrm{pH}$ values for strong growth and effective chlorinated solvent conversion. Several commercial strains of DHC are readily available for sites where natural populations of DHC are not present (addition of DHC during remediation can reduce technical uncertainty and increase confidence that the degradation process will operate effectively). Partial reductive dechlorination (i.e., terminating at cis-DCE in the anaerobic treatment zone) is sometimes observed but is not necessarily a problem. While cis-DCE is relatively difficult to degrade anaerobically, it is fairly easy to biodegrade aerobically (McCarty, 1993). Therefore, as cis-DCE migrates out of an anaerobic treatment zone, it will degrade readily in the presence of oxygen.

A variety of organic substrates and other electron donors have been developed and successfully tested over the years. These include soluble substrates (e.g., lactate, molasses, whey and other soluble sugars/carbohydrates), emulsions of insoluble liquids (e.g., emulsified vegetable oil such as Enhanced Oil Substrate, EOS $^{\circledR}$ ), insoluble liquid substrates (e.g., vegetable oil), insoluble viscous reagents such as innovative proprietary polymers of lactate (e.g., hydrogen release compound, $H R C^{\circledR}$ ), and various solids such as $\mathrm{EHC}^{\circledR}$ (a solid substrate that integrates carbon and zero valent iron - other solid substrates include chitin, mulch, peat or bark). Gases (e.g., hydrogen) have also been tested but with more limited experience.

Selection of the appropriate electron donor depends on site specific needs related to deployability (mobility, density, etc.) and sustainability (longevity in the target setting for the target plume). Of the common electron donors listed above, the relative mobility tends to decrease and the relative longevity tends to increase when moving from soluble substrates through the emulsions and insoluble substrates, to solids Figure 9). To meet the needs of the X-740 plume (i.e., requiring a longevity of "decades" based on the conceptual model), soluble substrates would degrade relatively quickly and would require repeated application along with the associated process monitoring. Conversely, insoluble liquid substrates, insoluble viscous substrates and solids, while having sufficient longevity, would be difficult to deploy in the highly heterogeneous Gallia and would likely significantly reduce the transmisivity of this zone. The optimum combination of mobility and longevity for the transmissive portion Gallia might be realized by oil emulsions. By carefully controlling the droplet size and charge, researchers have documented the ability to deploy over the required distances and have developed relatively straightforward design guidance. Because of the small droplet sizes and negative surface charges on the droplets, research on EOS $^{\circledR}$, for example, suggests that the oil deployment is not predicted by filtration concepts, but rather by collision and oil retention capacity relationships (Birk et al., 2006; Coulibaly and Borden, 2003; Jung and Borden, 2003). . 


\section{LONGEVITY OF CARBON SUBSTRATES}

(CONTINUUM OF SUBSTRATES)

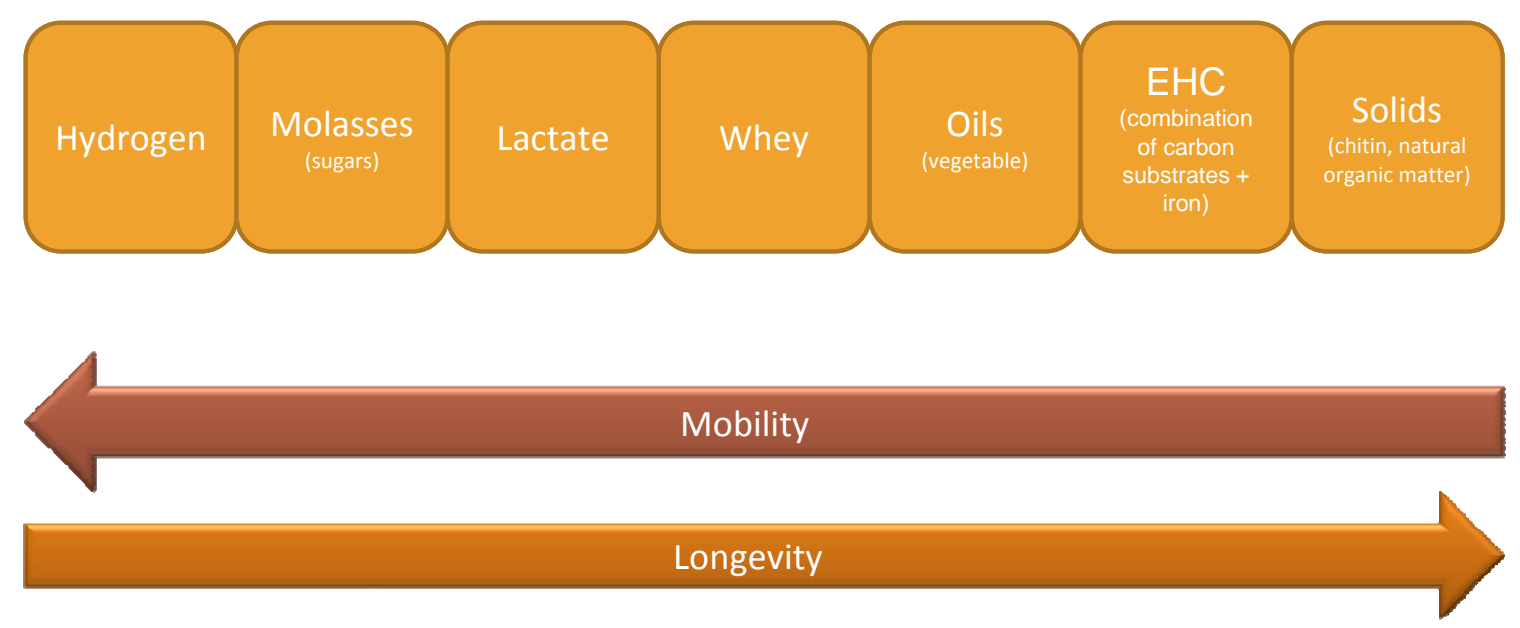

Figure 9. Relative mobility and longevity of various electron donor substrates.

Edible oil deployment results in the development of structured geochemical zones and serves to decrease chlorinated compound concentrations in two ways: 1) physical sequestration, which reduces effective aqueous concentration and mobility; and 2) stimulation of anaerobic, abiotic and cometabolic degradation processes. The idea of structured geochemical zones has been considered by many investigators; one example deployment was at the T-Area of the Savannah River Site (Riha, 2009) and the concept for T Area is depicted in Figure 10 - note that this concept is directly applicable to the X740 source area and plume. In the central deployment area, contaminant initially partitions into the added oil phase. Biodegradation of the added organic substrate depletes the aquifer of oxygen and other terminal electron acceptors and creates conditions conducive to anaerobic degradation processes. The organic substrate is fermented to produce hydrogen, which is used as an electron donor for anaerobic dechlorination by organisms such as Dehalococcoides. Daughter products leaving the central treatment zone are amenable to aerobic oxidation. Further, the organic compounds leaving the central deployment zone (e.g., methane and propane) stimulate and enhance down gradient aerobic cometabolism which degrades both daughter compounds and several parent cVOCs. Figure 10 depicts TCE concentration reduction processes (labeled in green) along with their corresponding breakdown products. 


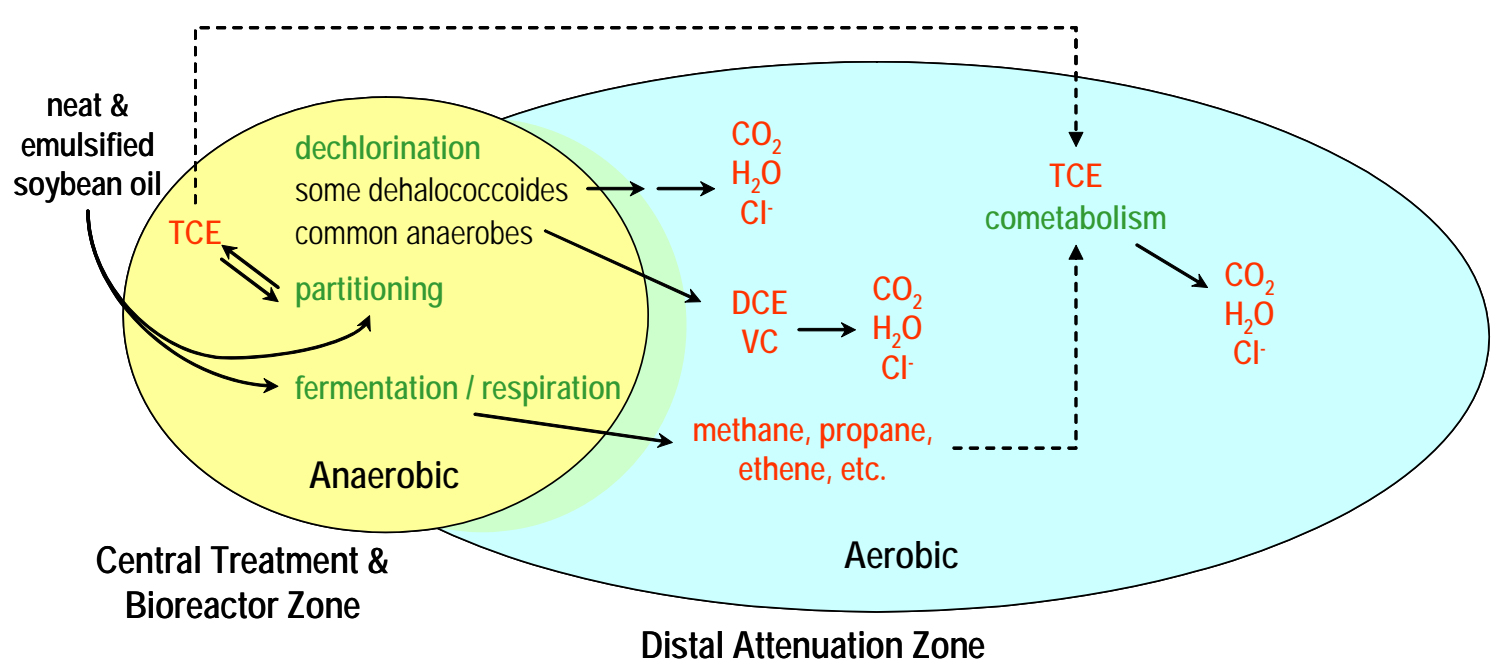

Figure10. Schematic of TCE concentration reduction processes using structured geochemical zones

The geochemistry of the aquifer is critical for effective bioremediation. DHC cultures are strict anaerobes and are most effective near neutral $\mathrm{pH}$ and strong reducing conditions. Table 1 provides the significant geochemical parameters needed for effective reductive dechlorination with DHC along with average values from the X-740 site. The conditions at the site are conducive to stimulate reductive dechlorination with the addition of a carbon source such as emulsified oil.

Table 1 -Geochemical Parameters for Reductive Dechlorination

\begin{tabular}{|l|l|l|}
\hline Parameter & $\begin{array}{l}\text { Optimal } \\
\text { Conditions }\end{array}$ & $\begin{array}{l}\text { PORT X-740 } \\
\text { Average Values }\end{array}$ \\
\hline DO & Low to zero & $1.5 \mathrm{mg} / \mathrm{L}$ \\
\hline pH & 5.5 to 8 & 6 to 7 \\
\hline $\begin{array}{l}\text { Alkalinity } \\
\text { (buffering capacity) }\end{array}$ & Present & 200 \\
\hline Sulfate & Low & $350 \mathrm{mg} / \mathrm{l}$ \\
\hline Nitrate & Low & low \\
\hline Redox & Low & No data \\
\hline
\end{tabular}

The review team consensus is that in situ bioremediation is potentially viable and conditionally recommended (contingent upon developing cost effective access and delivery using methods that have acceptable uncertainties and low technical/cost risks). As noted above, this technology could potentially be used in combination with upgradient passive drains to increase amendment longevity and to maximize the time contaminants remain in the treatment zone. 


\section{Permeable Reactive Barrier (CDM Alternative 5)}

Permeable reactive barriers were evaluated in detail ("Alternative 5") in the CDM Alternatives Evaluation Report. Permeable reactive barriers (PRBs) utilize reactive material placed in the subsurface to sorb, precipitate, or chemically or biologically transform contaminants in groundwater flowing through the PRB. PRBs are able to remediate a number of contaminant classes and have been demonstrated to be effective in treating environments that have proven recalcitrant to management through other remediation methods. PRBs are designed as passive treatment systems, with groundwater typically flowing under a natural gradient. Because contaminated groundwater must passively flow through the treatment zone, a thorough understanding of plume boundaries, aquifer hydrogeology, and reactive media characteristics is essential. The permeability of emplaced reactive materials must equal or exceed that of the aquifer over the operational lifespan of the PRB to ensure that contaminated groundwater flows through, not around, the reactive zone. PRBs generally have low maintenance costs and few operational costs aside from long-term performance monitoring, which is necessary to ensure sustained functioning of the system.

A number of reactive materials are available to treat TCE as groundwater flows through a PRB. Many PRBs rely on zerovalent iron (ZVI) to abiotically reduce and dehalogenate TCE and related chlorinated solvents. Recently, the selection and deployment of biowall systems that use long-lived solid organic materials such as mulch, compost, and peat has expanded - these systems biologically reduce and dehlogenate chlorinated solvents. The lifespan of ZVI and biowall systems are determined based on reaction and inactivation of iron or by depletion of carbonaceous substrates over time, respectively. In the case of biowalls, the lifespan can be increased by augmentation with liquid (or slurried) carbon sources, extending a system's useful life by a decade or longer (AFCEE, 2008).

Infrastructure for substrate addition should be incorporated into the initial system design. As with other PRBs, long-term performance monitoring is essential. Utilization of a biowall for treatment of the Portsmouth X-740 plume could be practical, but additional studies would be necessary to ascertain the type and quantity of organic materials best suited for treating TCE at existing concentrations and to make sure that the permeability of the barrier would be sufficient throughout the operational lifespan.

Our review team believes that PRBs are a viable option for the X-740 plume but with several caveats and conditions. In particular, the team favored a Biowall (or an iron enhanced biowall) over a ZVI only (abiotic) PRB. Because of the long treatment timeframes at X-740, a "biowall" with the provision for future revitalization would provide both near term performance and a cost effective a viable contingency response if extended performance times are required. PRBs should not be coupled with passive upgradient drains as these would increase the required timeframes. PRBs may not be needed if well designed source treatment, such as bioremediation, is implemented. This technology provide have little benefit upgradient of the barrier (i.e., in the source zone) and would adversely impact general water quality (e.g., low oxygen, high iron, etc.) downgradient of the wall and potentially impact water quality in groundwater discharge area(s). 
Access and Delivery

Access to the contaminated plume down to the Berea formation is straight forward and can be accomplished by direct push techniques (DPT) and standard drilling techniques. Temporary or permanent injection points or wells can be easily installed down to the Berea formation.

Amendment delivery to the groundwater plume at the $\mathrm{X}-740$ site is complicated by the stratigraphy and heterogeneous nature of the sediments, and by previous characterization (e.g., wells and soil borings) and remediation activities (e.g., the sand pipes installed throughout the stand of hybrid poplars). Based on the available data, any high pressure based injection techniques above the Berea will have technical risk and uncertainty and limited effectiveness. This can be seen in the previous Fenton's Reagent field injections, during which small volumes of injectants (30-50 gallons at 30-70 psi) often short circuited to the surface (daylighted) through previous borings and/or sand pipes. This daylighting phenomenon will also likely limit fracturing techniques to less than $10 \mathrm{ft}$ radius and result in multiple failures above the Berea (see box for more information on fracturing). Pressurized injections of amendments through wells or DPT rods will also likely result in limited lateral distribution and daylighting. The low permeability and lack of structural integrity of the Minford formation limits the potential for identifying and implementing Minford-targeted remediation technologies. Although fracturing could be successful in the Berea formation, the review team does not recommend breaching the structural integrity of this formation at the X-740 site. Lateral flow is very limited in the Berea formation and fracturing could increase contaminant migration at the site.

\section{Fracturing -- Supplemental Information}

Fracturing received significant focus in the CDM alternatives evaluation report. Fracturing can be used to increase permeability in tight and/or highly heterogeneous discontinuously layered sediments by using a propant such as sand. Amendments such as reactants (oxidants, EHC, HRC, etc.) can also be fractured into these types of contaminated sediments. Fracture propagations have been reported from a few feet to tens of feet and typically require pressures of 100 to $200 \mathrm{psi}$. The fracture fluid will take the path of least resistance towards higher permeability zones. These zones can be lithology induced or man made such as previous borings. Potential fracture applications for the $\mathrm{X}-740$ source and plumes include: a) install fractures with propant for multiple amendment additions, b) install fractures with amendment (EHC, etc.), and/or c) install fractures to connect sand lenses in Gallia formation.

The Gallia is significantly more permeable than the overlying Minford and the underlying Berea Sandstone. Thus, the Gallia is the primary zone of lateral groundwater and contaminant movement near X-740. As the primary transmissive zone in the system, the Gallia represents the most practical target for deployment of in situ remediation treatment reagents - despite a limited thickness, injection/extraction focused in this zone would provide maximum lateral impacts with minimal potential risk of failure or adverse collateral impacts. Data from pump tests, geological characterization studies, and 
conceptual models of the depositional processes, all suggest that the Gallia can be described as a "strongly heterogeneous" zone. This means that much of the flow and transport is through a highly permeable fraction of the Gallia (sand or gravel lenses, open pathways, etc) while relatively stagnant water exists in the remaining fraction.

As a result of this heterogeneity, any amendment addition or pumping process will not contact all of the Gallia formation. The TCE contamination will reside in both the permeable and less permeable materials within the Gallia. As the TCE is treated in the contacted zones, TCE will move by diffusion from the higher concentration zones to the lower concentration (treated) zones. Effective amendment delivery to the Gallia will require low flow rates and pressures to prevent the previously mentioned daylighting issues. Overall, the greatest probability of successful amendment delivery to treat the mobile TCE will be in the Gallia formation.

For access and delivery, the consensus of the review team is that low cost drilling and low pressure liquid reagent injection has the highest probability of success (viable and conditionally recommended). Fracturing was assessed as potentially viable but not recommended. As noted above, this technology could potentially be used in combination with upgradient passive drains to increase amendment longevity and to maximize the time contaminants remain in the treatment zone.

\subsection{Consolidated Recommendations and Example Combined Remedy}

\subsection{Summary of DOE EM 32 Review Team Findings and Recommendations}

The thoughts and recommendations of our review team have been blended with some of the key information from the CDM Alternatives Evaluation in Table 2. This table is roughly sorted in order of preference of the review panel (most preferred $\rightarrow$ least preferred) and categorizes each of the technologies that were determined to be viable by either our review team or by the CDM team. The technologies are then divided into two categories based on the consensus of our review team: 1) viable and conditionally recommended, and 2) viable and not recommended. In each case, a few key annotations are provided (i.e., what are the "conditions" associated with recommendations?, why did the team not recommend?). These categories represent the consensus of the review team based on a rapid, triage style, evaluation process and the categories are not based on detailed modeling or cost evaluation. As noted above, the results of our review will be most helpful if used in combination with the CDM Alternatives Evaluation and any follow-on modeling and design activities that are needed to confirm a remedy selection and to finalize a project. We encourage the Portsmouth site to use this information as a resource as they consider remediation technology options for the X-740 site. 
Table 2. Consolidated results of the EM-32 X-740 Technical Review

\begin{tabular}{|c|c|c|}
\hline Technology / Description & Review Team Recommendation & Issues/Conditions/Interdependencies \\
\hline $\begin{array}{l}\text { Enhanced Anaerobic Bioremediation / } \\
\text { In situ bioremediation using long lived } \\
\text { electron donor and low pressure liquid } \\
\text { deployment (as described above) }\end{array}$ & $\begin{array}{l}\text { Potentially viable and conditionally } \\
\text { recommended }\end{array}$ & $\begin{array}{l}\text { Recommended for the source zone only. } \\
\text { Focus on developing a structured treatment } \\
\text { zone downgradient for the plume. } \\
\text { Potential for synergy with passive } \\
\text { upgradient drains. }\end{array}$ \\
\hline $\begin{array}{l}\text { Permeable Reactive Barriers / } \\
\text { Alternative } 5 \text { in the CDM Alternatives } \\
\text { Evaluation -- Treatment zone } \\
\text { downgradient to reduce/destroy } \\
\text { contaminants flowing through the zone. } \\
\text { CDM evaluated both iron based barriers } \\
\text { and biobarriers. }\end{array}$ & $\begin{array}{l}\text { Potentially viable and conditionally } \\
\text { recommended }\end{array}$ & $\begin{array}{l}\text { More expensive than the enhanced } \\
\text { anaerobic bioremediation. PRBs } \\
\text { applicable in the downgradient plume. } \\
\text { Because of the long treatment timeframes } \\
\text { "biowall" variant (with provision for future } \\
\text { revitalization) should be considered. This } \\
\text { technology should not be coupled with } \\
\text { passive upgradient drains, and may not be } \\
\text { needed with well designed source } \\
\text { treatments. Little upgradient benefit (i.e., } \\
\text { in the source zone); would adversely } \\
\text { impact general water quality nearer the } \\
\text { groundwater discharge area(s). }\end{array}$ \\
\hline $\begin{array}{l}\text { Passive Upgradient Drains / } \\
\text { System to divert water around the } \\
\text { contaminated source zone and plume (as } \\
\text { described above) }\end{array}$ & $\begin{array}{l}\text { Potentially viable and conditionally } \\
\text { recommended }\end{array}$ & $\begin{array}{l}\text { Does not destroy or remove contaminant } \\
\text { and should be used in combination with a } \\
\text { primary technology (like bioremediation) } \\
\text { that would benefit from reduced water } \\
\text { inflow and a longer residence-reaction } \\
\text { time of contaminants. }\end{array}$ \\
\hline $\begin{array}{l}\text { Enhanced Anaerobic Bioremediation / } \\
\text { Alternative } 2 \text { in the CDM Alternatives } \\
\text { Evaluation - pressurized injection of liquid } \\
\text { carbon substrates in the source zone and/or } \\
\text { the downgradient zone }\end{array}$ & Potentially viable but not recommended & $\begin{array}{l}\text { Use of pressurized injections for liquid } \\
\text { reagents at this site are likely to result in } \\
\text { reagent bypass and daylighting. The } \\
\text { review team favors a lower flow/pressure } \\
\text { design basis. }\end{array}$ \\
\hline
\end{tabular}




\begin{tabular}{|c|c|c|}
\hline $\begin{array}{l}\text { In Situ Chemical Oxidation / } \\
\text { Oxidant blending using solid amendments } \\
\text { (e.g., permanganate) in the source area } \\
\text { down through Minford, Gallia and upper } \\
\text { layer of Berea (as described above) }\end{array}$ & Potentially viable but not recommended & $\begin{array}{l}\text { Deployable technology but relatively } \\
\text { costly. This variant of ISCO would be } \\
\text { more effective than the liquid based } \\
\text { injections and would eliminate daylighting. }\end{array}$ \\
\hline $\begin{array}{l}\text { In Situ Bioremediation / } \\
\text { Alternative } 1 \text { in the CDM Alternatives } \\
\text { Evaluation - fracturing based injection of a } \\
\text { solid amendment (EHC) into the source } \\
\text { zone and/or the downgradient zone }\end{array}$ & Potentially viable but not recommended & $\begin{array}{l}\text { The review team expressed concern about } \\
\text { the appropriateness of high pressure } \\
\text { fracturing techniques at the X-740 site. } \\
\text { This fracturing method introduces } \\
\text { significant technical and project } \\
\text { uncertainties and risks. }\end{array}$ \\
\hline $\begin{array}{l}\text { In Situ Chemical Oxidation / } \\
\text { Alternative } 3 \text { in the CDM Alternatives } \\
\text { Evaluation - pressurized injection of liquid } \\
\text { oxidant in the source zone and/or the } \\
\text { downgradient zone }\end{array}$ & Potentially viable but not recommended & $\begin{array}{l}\text { Use of pressurized injections for liquid } \\
\text { reagents at this site are likely to result in } \\
\text { reagent bypass and daylighting. Oxidant } \\
\text { lifetimes are much too short for the } \\
\text { conditions at in the X-740 source and } \\
\text { plume. Oxidant is best suited to source } \\
\text { and near source conditions, there is } \\
\text { minimal value of downgradient injection. }\end{array}$ \\
\hline $\begin{array}{l}\text { Electrical Resistance Heating / } \\
\text { Alternative } 4 \text { in the CDM Alternatives } \\
\text { Evaluation - source zone only }\end{array}$ & Potentially viable but not recommended & $\begin{array}{l}\text { Expensive and energy intensive - review } \\
\text { team assessed well designed } \\
\text { bioremediation as a better match to this } \\
\text { site (if aggressive source action were } \\
\text { deemed appropriate by the Portsmouth } \\
\text { team, solid oxidant blending is rater higher } \\
\text { than heating). }\end{array}$ \\
\hline
\end{tabular}




\subsection{Example of a Combined Remedy for the X-740 Plume}

We have assembled a descriptive example to illustrate a potential remedial strategy for the X-740 source and plume. This combined remedy example assumes: 1) subsurface access primarily using direct push technology; 2) treatment using low pressure injection of long lived amendments in the source zone to reduce mass and flux, 3) development of a structured treatment zone to partially treat downgradient contamination, and 4) possible use of uppgradient passive drains.

The central action in this suite of technologies is anaerobic bioremediation in the source zone. Figure 11 is a cross section and plan view schematic of a hypothetical source zone bioremediation. We assume a long-lived donor substrate (such as a dilution of commercially available concentrated vegetable oil emulsion, such an EOS or equivalent). The injection would rely on an array of wells with screen zones across the Gallia (e.g., 5 $\mathrm{ft}$ screens that include the nominal $1 \mathrm{ft}$ or so of Gallia) in the source zone. The description below assumes DPT wells. "Standard” wells would be appropriate and provide relatively robust performance and greater engineering flexibility if installation costs could be controlled. The general philosophy of this example is the use of low pressure and low flow combined with long injection periods for the reagent deployment. Once the well array is installed, operators would extract source zone water into a tank air strip TCE if desired, add emulsion and reinject into source zone wells by gravity feed or low flow metering. This deployment strategy would saturate the targeted Gallia interval with diluted emulsion, minimize daylighting and provide a long-term residual treatment zone. Once reducing conditions are met, the site could be bio-augmented with DHC, if needed, to maximize contaminant degradation.

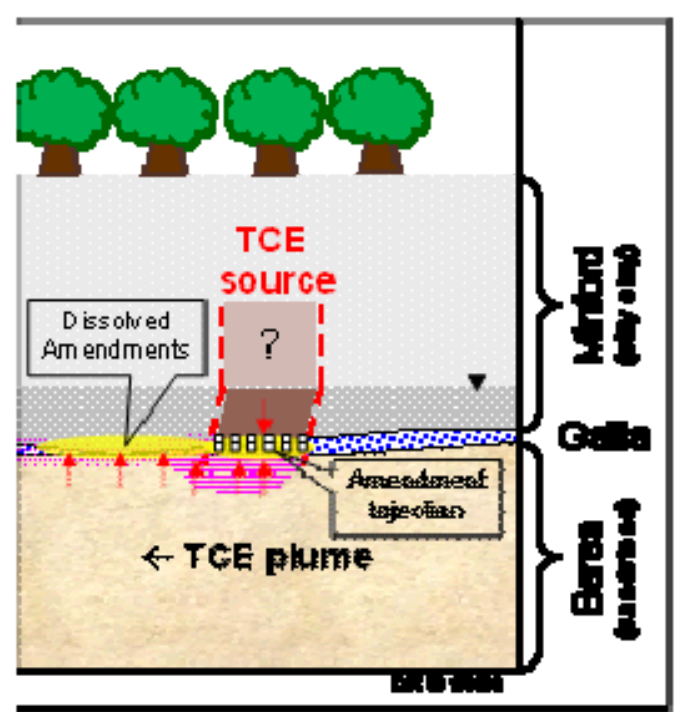

Cross Section

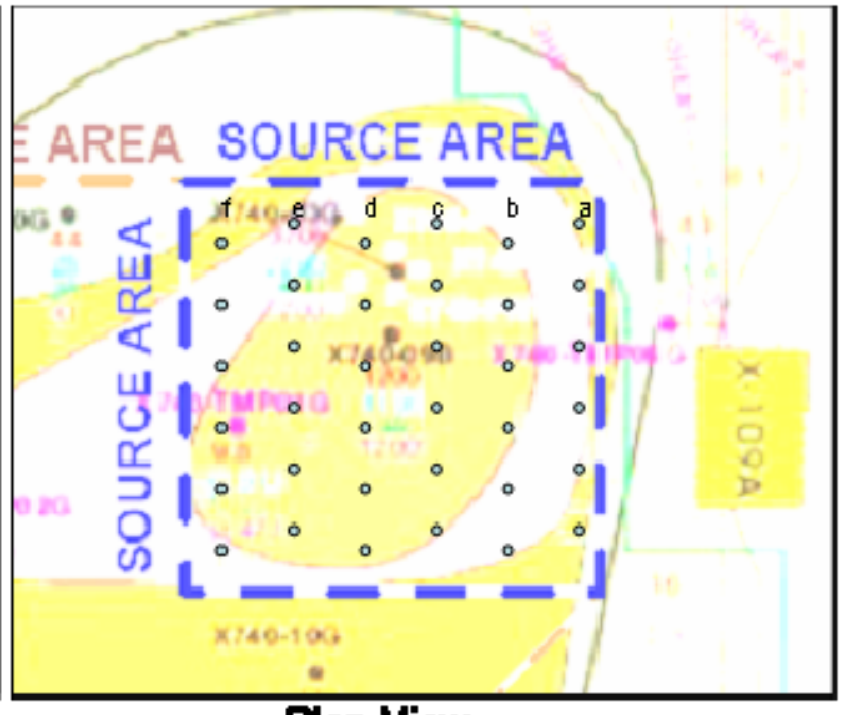

Plen Vian

Figure 11. Simplified schematic of anaerobic bioremediation targeting the Gallia in the $X-740$ source zone. 
The spacing of the wells and volumes pumped are calculated based on site specific characteristics (e.g., assumed injection zone thickness, porosity, etc.). Using parameters consistent with those documented in the CDM Alternatives Evaluation and recent modeling, a reasonable injection array might cover an area approximately $75 \mathrm{ft} \times 75 \mathrm{ft}$ and consist of 36 injection points installed at a spacing of 6 to $8 \mathrm{ft}$ on centers (see Figures 11 and 12, and Table 2). The actual operation would be performed in phases - for each row, water is extracted, blended with amendment concentrate, and then injected (Figure 12). In this hypothetical deployment, the use of two tanks allows simultaneous extraction from a downgradient row, while injecting in an upgradient row. This two tank system also allows water to be pumped initially into a collection tank (and sparged if desired to remove TCE) and then transferred to an injectate tank where the amendment is added. Low flow pneumatically operated extraction pumps (e.g., bladder pumps) are assumed and an entire row of extraction pumps is operated on a single compressor with a timer/solenoid control system. If larger, "standard," wells are installed, the up-hole extraction support equipment can be simplified (e.g., by eliminating the timer/solenoid control system) and the down-hole equipment changed to pumps that evacuate each well in response to water level recovery.

Injection is performed by gravity flow to slowly infuse the reagent into the target zone. Operations personnel monitor the process and move equipment from row to row until all six rows are complete (e.g., 15 weeks). These various phases are depicted on Figure 12. Table 3 provides additional details about the assumed flow rates and quantities of water and amendment. In this example, two totes (330 gallons each) of concentrated emulsion are deployed in each row of wells. Each well is conservatively assumed to flow between 0.05 and $0.2 \mathrm{gpm}$ and each row of six wells is assumed to require a total injectate volume less than 5000 gallons. A scoping cost estimate suggests that costs for the source zone bioremediation should be between $\$ 1,000,000$ and $\$ 2,000,000$ (note that several conservative assumptions were included and these costs might be able to be reduced). A schedule for the hypothetical source zone treatment is provided in Figure 13. Finally, if the monitoring data in the source zone suggest a need, commercially available DHC organisms could be added through the DPT array to accelerate degradation.

The source zone bioremediation would be supplemented to achieve a combined remedy though downgradient monitoring of flux reduction and measurements that would document microbial enahancements (see Riha et al, 2009 for an historical example of such a combined remedy and the monitoring used to document downgradient enahancement). Finally, if calculations and modeling indicated a substantive benefit, the Portsmouth team could supplement the source zone and downgradient remedy by installing and upgradient passive drain.

Note that this section describes a rough concept for hypothetical deployment, and is not prescriptive. Instead, this section is intended to serve as a simple example and to encourage the Portsmouth team, DOE, contractor and regulators to work together to develop their own creative and effective solution for the X-740 source and plume. 


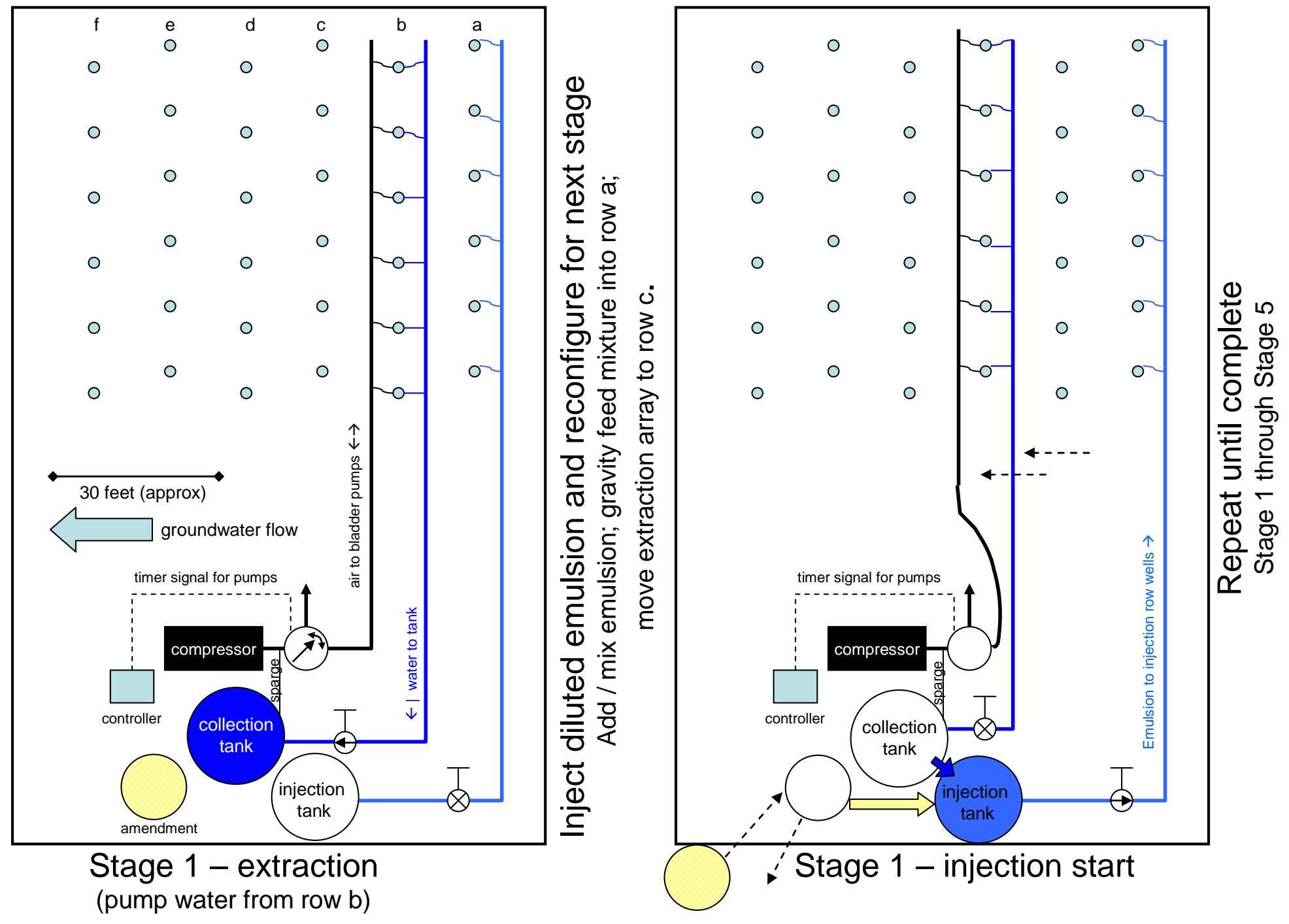

Figure 12. Detail diagram of hypothetical $X-740$ source zone anaerobic bioremediation 
Table 3. Parameters supporting hypothetical design

\begin{tabular}{|c|c|c|}
\hline \multicolumn{3}{|l|}{ Scenario: } \\
\hline 1 & desired treatment width & 70 feet \\
\hline 2 & desired treatment length & 70 feet \\
\hline 3 & assumed radius for injection & 10 feet \\
\hline 4 & resulting number of wells/row & 6 \\
\hline 5 & resulting number of rows & 6 \\
\hline \multicolumn{3}{|c|}{ Key Site Characteristics: } \\
\hline 6 & Jnominal Gallia thickness & 1 foot \\
\hline 7 & porosity & 0.4 \\
\hline 8 & fraction pref flow & 0.75 \\
\hline 9 & assumed flow to/from wells (low) & $0.05 \mathrm{gpm}$ per well \\
\hline 10 & assumed flow to/from wells (high) & $0.2 \mathrm{gpm}$ per well \\
\hline \multicolumn{3}{|c|}{ Extraction Volume: } \\
\hline 11 & Jrequired volume (based on $3,6,7,8$ ) & 4230 total gallons per row \\
\hline 12 & volume per well (based on 4,11) & 705 gallons extracted per well \\
\hline 13 & pumping times required: & \\
\hline & high flow (based on 10,12 ) & 2.4 days at high flow \\
\hline & low flow (based on 9,12) & 9.8 days at low flow \\
\hline \multicolumn{3}{|c|}{ Injectate Volume: } \\
\hline 14 & typical water:amendment ratio & 10 parts water to 1 part concentrated emulsion \\
\hline 15 & amendment per row (based on 11,14) & 423 gallons of amendment per row (theory) \\
\hline 16 & total injectate per row (based on 11,14 ) & 4653 total gallons blended with amendment (theory) \\
\hline 17 & total injectate per row (based on 4,17 ) & 775 gallons to be injected per well (theory) \\
\hline 18 & round amendment to tote quantities (based on 15) & 2 totes ( 330 gallons each) per row \\
\hline 19 & adjusted total injectate volume (based on 11,18 ) & 4890 total gallons per row (assuming use of full totes) \\
\hline 20 & adjusted total injectate per well (based on 4,19 ) & 815 gallons injected per well \\
\hline 21 & injection times required & \\
\hline & high flow (based on 10,20 ) & 2.8 days at high flow \\
\hline & low flow (based on 9,20 ) & 11.3 days at low flow \\
\hline \multicolumn{3}{|l|}{ Costs: } \\
\hline 22 & total time for operations/deployment & 15 weeks \\
\hline 23 & number of employees for operation/deployment (FTEs) & 2 \\
\hline 24 & loaded employee costs & 8000 \$ per week per FTE \\
\hline 25 & subtotal for operation/deployment personnel & $\$ 240,000$ \\
\hline 26 & Jengineering/shutdown support (assume the same as 25) & $\$ 240,000$ \\
\hline 27 & ]amendment (assume $\$ 12,000$ per tote) & $\$ 120,000$ \\
\hline 28 & ]equipment (pumps, compressor, 5,000 gal. tanks, etc) & $\$ 150,000$ \\
\hline 29 & construction crew costs (assume the same as 28) & $\$ 150,000$ \\
\hline 30 & ]dpt array installation & $\$ 150,000$ \\
\hline 31 & ]contingencies & $\$ 0$ to $\$ 1,000,000$ \\
\hline 32 & Total Costs (approximate) & $\$ 1,000,000$ to $\$ 2,000,000$ \\
\hline
\end{tabular}


SAMPLE FIELD DEPLOYMENT SCHEDULE FOR EXAMPLE "STRUCTURED REACTION ZONE" BIOREMEDIATION (see schematic diagram for layout)

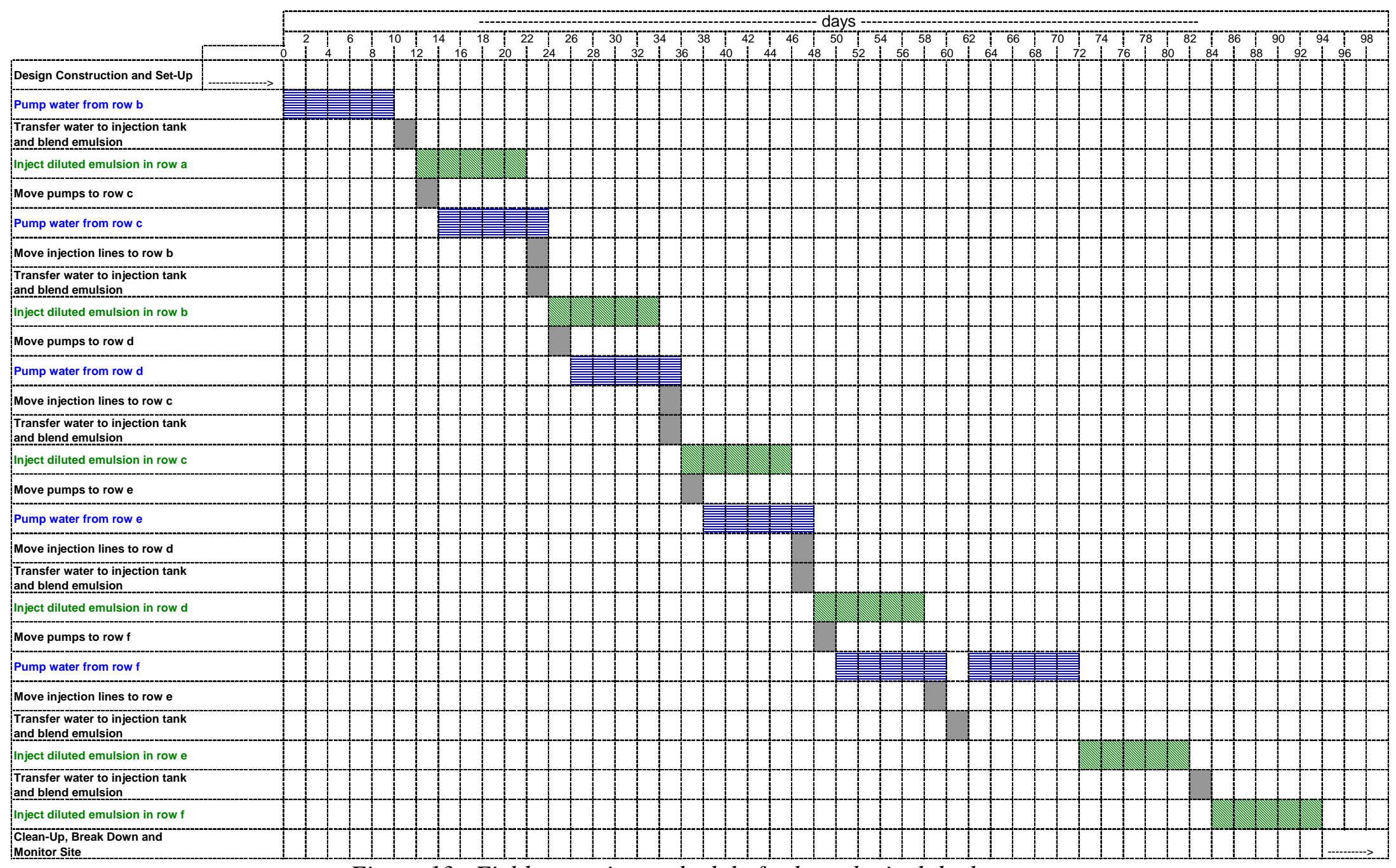

Figure 13. Field operations schedule for hypothetical deployment 


\section{References}

AFCEE (Air Force Center for Environmental Excellence). 2008. Technical Protocol for Enhanced Anaerobic Bioremediation Using Permeable Mulch Biowalls and Bioreactors. Prepared by Parsons Infrastructure \& Technology Group, Inc. under contracts F4162400-D-8024 and F41624-03-D-8613.

Birk, G, Borden, R. and Borden, A., 2006. Enhanced Anaerobic Bioremediation Using Edible Oils. Short Course Presented at the Fifth International Conference on Remediation of Chlorinated and Recalcitrant Compounds, May 22, 2006, Monterey CA.

Borden, 2006. Protocol for Enhanced In Situ Bioremediation Using Emulsified Edible Oil. Environmental Security Technology Certification Program (ESTCP).

Coulibaly, K. M. and R. C. Borden, 2003. Distribution of Edible Oil Emulsions and Permeability Loss in Sandy Sediments, Seventh International Symposium on In situ and On Site Bioremediation, Orlando FL, 2003.

DOE (U.S. Department of Energy), 1998. Quadrant III Cleanup Alternative study/Corrective Measures Study Final report for the Portsmouth Gaseous Diffusion Plant, DOE/OR/12-1360\&D3, Piketon, Ohio.

EPA (Environmental Protection Agency), 1999. Field Applications of Insitu Remediation Technologies: Chemical Oxidation, EPA 542-R-98-008, United States Environmental Protection Agency Office of Solid Waste and Emergency Response, available at http//clu-in.org.

Jung, Y. and R. C. Borden, 2003. Subsurface Transport of Emulsified Edible Oil: 3D Sandbox Studies, Seventh International Symposium on In situ and On Site Bioremediation, Orlando FL, 2003.

McCarty, P.L., 1993. In Situ Bioremediation of Chlorinated Solvents, current Opinion in Biotechnology, 4(3), 323-330.

Riha, B.D, Looney, B.B., Noonkester, J., and Hyde, K., 2009. Treatability Study for Edible Oil Deployment for Enhanced cVOC Attenuation for T-Area, Savannah River Site: Interim Report - Year One. SRNL-RP-2009-00539, Savannah River National Laboratory, Aiken, SC. 


\title{
Appendix A. Independent Technical Review Team Charter
}

\author{
Charter for DOE Independent Technical Review Team \\ Technical Evaluation of the Path Forward for the X-740 Groundwater Remedy \\ Portsmouth Gaseous Diffusion Plant \\ Portsmouth, Ohio
}

The Department of Energy (DOE) Portsmouth Paducah Project Office (PPPO) is conducting the X-740 groundwater remedy for trichloroethene (TCE) in accordance with a Decision Document that was issued by Ohio EPA on May 1999 (Ohio EPA's Decision Document for Quadrant III of the US DOE Portsmouth Facility Piketon Ohio), and a Work Plan that was approved by Ohio EPA on May 7, 2008 (Work Plan for the X-740 Groundwater Plume Optimization at the Portsmouth Gaseous Diffusion Plant, Piketon, Ohio). The Work Plan divides the remedy into three phases.

Phase I, II, and III of the remedy was completed during fiscal year (FY) 2008. The Independent Technical Review (ITR) Team will focus their evaluation on providing a recommendation for the X-740 groundwater plume. Results of the ITR Team evaluation will be used in determining a path forward for the X-740 groundwater plume.

Section 6 of the Work Plan contains specific criteria for the end point determination. According to the Work Plan, injection phases will continue throughout all or portions of the groundwater plume where TCE is present at $50 \mathrm{ppb}$ or higher until at least one of the following criteria are met:

1. Groundwater monitoring results for TCE are at or below $50 \mu \mathrm{g} / \mathrm{L}$ in all or a portion of the groundwater sampling locations identified in Table 6 of the Work Plan, or

2. The remedy is no longer effective in removing additional TCE mass from the target area.

The Work Plan further identifies one distinct process that will be used to determine when the remedy is no longer effective in removing TCE mass. This process is described in detail in the Work Plan, but in summary it is:

a) A smooth curve of the average TCE groundwater concentration shows $10 \%$ or less between injection events.

A meeting was held in May 2009 between the DOE and Ohio EPA to review the 6-month post In-Situ Chemical Oxidation (ISCO) groundwater sampling results. Ohio EPA indicated that ISCO was not having a measurable effect after three injections and provided a letter to DOE to complete a special study at the X-740 area on May 28, 2009. On June 26, 2009, DOE requested a 90 day extension to further evaluate other remedial alternatives to effectively address the groundwater plume at the X-740 area. On July 10, 2009, DOE received the extension approval from the Ohio EPA. 
Additionally, in 1999 a corrective action was implemented primarily to address the volatile organic chemical contamination (TCE) in the X-740 groundwater. The DOE planted 766 one year old hybrid poplar trees over 2.6 acres of the groundwater plume. DOE implemented two planting methods; some of the trees were planted in trenches that were 10 feet deep, while others were planted in borings that were also 10 feet deep. Sand pipes were installed in the trenches to enhance the uptake of the groundwater into the trenches. After several years of monitoring the groundwater plume, it was apparent that the selected remedy was not remediating the contaminant plume at this unit and was deemed a failed remedy by Ohio EPA in 2007. 
The Charter for the DOE HQ ITR Team is to:

- Review the Work Plan (see Attachment) for the remedy with specific emphasis on the determination of the end point

- Review the letter report from Ohio EPA following the third series of injection events.

- Review groundwater data from the baseline, Phase I, II, and III sampling events.

- Determine the feasibility of declaring Technical Impracticability (see Decision Document) and proceeding with RSI Independent Review Report.

- If Technical Impracticability is recommended for the current technology, then provide a summary of other cost effective technologies that could be implemented.

- Provide a briefing and report to DOE-PPPO and site contractors that summarize the team's evaluation and makes recommendations for the completion of the remedy.

- Prepare for and participate in up to two meetings with the DOE, regulatory agencies, and/or the public, as required.

In completing this scope, the ITR Team should plan for a two day site visit to the Portsmouth Gaseous Diffusion Plant. During the site visit, DOE-PPPO and contractors will present information concerning the X-740 site and remedial activities at the site and the ITR Team will be allowed to visit the X-740 site. Additionally, the ITR Team should plan on providing a draft report for factual accuracy review and a final report. The schedule for ITR Team activities will be developed after the team is created; however, the draft report is expected within 4 weeks following the site visit. The final report is expected 2 weeks following the team's receipt of any factual accuracy comments.

The DOE-PPPO project and technical contact for the team will be Melda Rafferty (740-8975521; melda.rafferty@1ex.doe.gov). 


\section{X-740 Documents}

\begin{tabular}{|c|c|}
\hline & Document Title \\
\hline 1 & $\begin{array}{l}\text { Ohio EPA's Decision Document for QuadrantI II of the US DOE } \\
\text { Portsmouth Facility Piketon Ohio, Ohio EPA, May } 1999 .\end{array}$ \\
\hline 2 & $\begin{array}{l}\text { Work Plan for the X-740 Groundwater Plume Optimization at the } \\
\text { Portsmouth Gaseous Diffusion Plant, Piketon, Ohio, DOE/PPPO/03- } \\
\text { 0061\&D1, U.S. Department of Energy, February } 2008 \text {. }\end{array}$ \\
\hline 3 & $\begin{array}{l}\text { X-740 Solid Waste Management Unit Class V Injection Wells - May } \\
2008 \text { Monthly Operating Report PPPO/03-171-08, U.S. Department of } \\
\text { Energy. }\end{array}$ \\
\hline 4 & $\begin{array}{l}\quad X-740 \text { Solid Waste Management Unit Class V Injection Wells - July } \\
2008 \text { Monthly Operating Report PPPO/03-208-08, U.S. Department of } \\
\text { Energy. }\end{array}$ \\
\hline 5 & $\begin{array}{l}\text { X-740 Solid Waste Management Unit Class V Injection Wells- } \\
\text { September } 2008 \text { Monthly Operating Report PPPO/03-101-09, U.S. } \\
\text { Department of Energy. }\end{array}$ \\
\hline 6 & $\begin{array}{l}\text { Ohio EPA Letter X-740 Solid Waste Management Unit (SWMU) } \\
\text { Groundwater Plume Additional Work, May } 2009 .\end{array}$ \\
\hline 7 & $\begin{array}{l}\text { Untitled data packet containing analytical results from Phase I, II, and } \\
\text { III groundwater samples. Includes a TCE summary and two figures } \\
\text { displaying the results. }\end{array}$ \\
\hline 8 & $\begin{array}{l}\text { Five-Year Evaluation Report for the X-740 Phytoremediation } \\
\text { Project at the Portsmouth Gaseous Diffusion Plant, Piketon, Ohio, } \\
\text { DOE/OR/11-3135\&D1, U.S. Department of Energy, October, } 2003 .\end{array}$ \\
\hline
\end{tabular}




\begin{tabular}{|c|l|l|}
\hline 9 & $\begin{array}{l}\text { Addendum to the Five-Year Evaluation Report for the X-740 } \\
\text { Phytoremediation Project at the Portsmouth Gaseous Diffusion Plant, } \\
\text { Piketon, Ohio, DOE/OR/11-3135\&D1/A1, U.S. Department of Energy, } \\
\text { December, 2003. }\end{array}$ & \\
\hline 10 & $\begin{array}{l}\text { Supplemental Evaluation to the 2003 Five-Year Evaluation report } \\
\text { for the X-740 Phytoremediation System at the Portsmouth Gaseous } \\
\text { Diffusion Plant, Piketon, Ohio, DOE/PPPO/03-0038\&D1, U.S. } \\
\text { Department of Energy, January, 2007. }\end{array}$ & $\begin{array}{l}\text { X-740 TCE Plume Modeling and Remedial Alternative Update } \\
\text { Presentation, CDM, September 2009. }\end{array}$ \\
\hline 11 & $\begin{array}{l}X \text {-740 Plume Assessment Report (RSI Independent Review), June } \\
2009 .\end{array}$ & \\
\hline 12 & & \\
\hline
\end{tabular}

